\title{
Assessing chronic fish health: An application to a case of an acute exposure to chemically treated crude oil
}

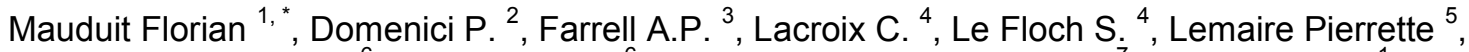 \\ Nicolas-Kopec A. ${ }^{6}$, Whittington M. ${ }^{6}$, Zambonino-Infante Jose-Luis ${ }^{7}$, Claireaux Guy ${ }^{1}$
}

${ }^{1}$ Université de Bretagne Occidentale, LEMAR (UMR 6539), Centre Ifremer de Bretagne, 29280

Plouzané, France

${ }^{2}$ CNR-IAMC, Località Sa Mardini, 09072 Torregrande, Oristano, Italy

${ }^{3}$ University of British Columbia, Department of Zoology and Faculty of Land and Food Systems, 2357

Main Mall, University of British Columbia, Vancouver, BC, V6T 1Z4, Canada

${ }^{4}$ CEDRE, Research Department, 715 rue Alain Colas, CS 41836, Brest 29218-Cedex 2, France

${ }^{5}$ Total Fluides, 24 Cours Michelet, La Défense 10, 92069 Paris La Défense-Cedex, France

${ }^{6}$ The International Tanker Owners Pollution Federation Limited (ITOPF), 1 Oliver's Yard, 55 City Road, London EC1Y $1 \mathrm{HQ}$, United Kingdom

${ }^{7}$ Ifremer, LEMAR (UMR 6539), Centre Ifremer de Bretagne, 29280 Plouzané, France

* Corresponding author : Florian Mauduit, email address : florian.mauduit@ifremer.fr

\begin{abstract}
:
Human alteration of marine ecosystems is substantial and growing. Yet, no adequate methodology exists that provides reliable predictions of how environmental degradation will affect these ecosystems at a relevant level of biological organization. The primary objective of this study was to develop a methodology to evaluate a fish's capacity to face a well-established environmental challenge, an exposure to chemically dispersed oil, and characterize the long-term consequences. Therefore, we applied high-throughput, non-lethal challenge tests to assess hypoxia tolerance, temperature susceptibility and maximal swimming speed as proxies for a fish's functional integrity. These whole animal challenge tests were implemented before ( 1 month) and after ( 1 month) juvenile European sea bass (Dicentrarchus labrax) had been acutely exposed $(48 \mathrm{~h})$ to a mixture containing $0.08 \mathrm{~g} \mathrm{~L}-1$ of weathered Arabian light crude oil plus 4\% dispersant (Corexit@ EC9500A), a realistic exposure concentration during an oil spill. In addition, experimental populations were then transferred into seminatural tidal mesocosm ponds and correlates of Darwinian fitness (growth and survival) were monitored over a period of 4 months. Our results revealed that fish acutely exposed to chemically dispersed oil remained impaired in terms of their hypoxia tolerance and swimming performance, but not in temperature susceptibility for 1 month post-exposure. Nevertheless, these functional impairments had no subsequent ecological consequences under mildly selective environmental conditions since growth and survival were not impacted during the mesocosm pond study. Furthermore, the earlier effects on fish performance were presumably temporary because re-testing the fish 10 months post-exposure revealed no significant residual effects on hypoxia tolerance, temperature susceptibility and maximal swimming speed. We propose that the functional proxies and correlates of Darwinian fitness used here provide a useful assessment tool for fish health in the marine environment.
\end{abstract}




\section{Highlights}

- An ecologically relevant methodology to assess fish health is proposed. Dispersant and oil alone exposure did not affect fish health. Dispersant-treated oil exposure temporarily affected fish health.

- Health recovery occurred and no long-term ecologically relevant consequences were observed.

Keywords: Fish, Oil spill, Dispersant, Biomarkers, Physiological integrity, Ecological performance, Temperature, Hypoxia, Swimming, Growth

\section{Abbreviations}

- CONT, Control;

- $\mathrm{CT}_{\max }$, Critical thermal maximum;

- DISP, Dispersant;

- GC-MS/MS, gas chromatography-tandem mass spectrometry;

- ILOS, Incipient lethal oxygen saturation;

- NEBA, Net environmental benefit analysis;

- OIL, Oil;

- $\quad$ OIL + DISP, Chemically dispersed oil;

- $\mathrm{PAH}$, Polycyclic aromatic hydrocarbons;

- TE, Time to exhaustion;

- TLOE, Time to loss of equilibrium;

- TPH, Total petroleum hydrocarbon;

- $\mathrm{U}_{\max }$, Maximal swimming speed 


\section{Introduction}

Human population densities in coastal regions are about three-times higher than global average (Small and Nicholls, 2003). This demographic concentration and associated activities put considerable pressure on marine ecosystems, as revealed by indices of ecological imbalances such as eutrophication, increased number and severity of hypoxic events, loss of habitat and loss of biodiversity (UNEP, 2006). To preserve the ecological and economical services provided by coastal ecosystems, it is crucial that our current understanding of their functioning be improved and particularly that the resilience of the species that occupy them be better assessed.

In human medicine, health is viewed as a cumulative outcome that informs clinicians about the present capacity of a patient to do what she/he has to do. Yet, health also informs about the past of that patient, as her/his current status integrates the latent and residual effects of earlier life conditions and experiences. Moreover, health also incorporates elements about the future of that person, in relation with her/his vulnerability and resilience to everyday life conditions and change (Deem et al., 2001, Hertzman et al., 2001, Hanisch et al., 2012 and Stephen, 2014).

The notion of health as it is defined in humans provides a valuable conceptual framework for methodologies aimed at assessing the impact of anthropogenic activities, and mitigation strategies, upon marine organisms. Unfortunately, at present time animal health is too poorly defined to be useful in ecotoxicological impact assessment. A review of the literature indeed shows that animal health is generally limited to present time, is mostly concerned with proximate causes of death or 
disease, rarely accounts for cumulative effects and commonly fails to include the notions of resilience and vulnerability of populations. As a result there is, to date, no integrated indicator of "coping ability" that could be used to gauge one animal's health.

In fish, common and long-standing knowledge indicates that hypoxia tolerance, thermal susceptibility and swimming capacity are ecologically relevant indicators of functional integrity and are, therefore, useful markers of fish health (Fry, 1947, Tierney and Farrell, 2004, McKenzie et al., 2007, Claireaux et al., 2005, Claireaux et al., 2013 and Castro et al., 2013). For instance, the altered ability to tolerate hypoxic conditions observed in the common sole (Solea solea) following fuel exposure (48 $\mathrm{h}$ in $1 / 200 \mathrm{v} / \mathrm{v}$ fuel No.2) was associated with reduced growth and survival in seminatural field mesocosm (Claireaux et al., 2004). Likewise, using the same field site, Handelsman et al. (2010) and Claireaux et al. (2013) reported that hypoxia tolerance, temperature susceptibility and swimming performances determined survivorship in juvenile sea bass.

As recent events continue to show, resorting to chemical dispersants to deal with oil spills in coastal environments is a controversial matter. At the centre of this controversy is whether the risk of ecological effects increases or decreases when chemical dispersants are used, and whether the response strategy should favour the preservation of landscape and surface organisms by using dispersant or should protect the water column by refraining from treating with chemicals. However, lacking for a proper risk assessment is an adequate understanding of the mechanisms through which toxic effects, classically observed at subcellular level, ripple through 
higher organisational levels to affect fish populations and ecosystems (Brander et al., 2015). Cellular and molecular biomarkers indeed dominate toxicological assessments and it remains common practice to extrapolate effects at higher levels of biological complexity from information derived from these lower level indicators. Yet, it has long been recognized that the best approach for establishing causalities across hierarchical scales is to proceed from observation of emergent properties at a given organisational level through to studying the underlying mechanisms occurring at organisational levels situated below (Rosen, 1969). Implementing such approaches is one key to successfully bridge the gap between toxicology and ecology (Solomon et al., 2008).

To this background, and by combining measurements of hypoxia tolerance, thermal susceptibility and swimming performance, the aim of the present work was to design a methodology to assess the health of a fish population in the form of an integrated evaluation of individual's capacity to face everyday life challenges. We validated this methodology by monitoring, over a year, and under laboratory and field conditions, the effect of exposure to chemical dispersant, crude oil and a mixture of both upon the health of a population of 718 juveniles European sea bass (Dicentrarchus labrax).

\section{Materials and methods}

\subsection{Animals}

Juvenile European sea bass (Dicentrarchus labrax; age $1+; \mathrm{N}=718$ ) were obtained from a local fish farm (Aquastream, Lorient, France). On arrival in the laboratory (Ifremer, Brest, France) fish $(11.27 \pm 1.06 \mathrm{~cm}$ in length and $17.74 \pm 4.96 \mathrm{~g}$ in body 
mass) were placed in a 2000-L indoor tank and acclimated for two months to local photoperiod, temperature and salinity. They were fed daily ad libitum with a commercial diet (Neo Start Coul 2, Le Gouessant, France). Two weeks before experiments started, fish were anaesthetized (phenoxyethanol; $0.2 \mathrm{~mL} \mathrm{~L}^{-1}$ ) and individually implanted subcutaneously with an identification tag (RFID; Biolog-id, France). Fish were starved for $24 \mathrm{~h}$ before any manipulation or experiment. The animal care protocols were in conformity with current rules and regulations in France.

\subsection{Experimental protocol}

The experimental schedule is outlined in Fig. 1. Fish health was assessed via a suite of challenge tests conducted 1 month before (February, $\mathrm{T}^{\circ} \mathrm{C}=10$ ), 1 month after (May, $\mathrm{T}^{\circ} \mathrm{C}=15$ ) and 10 months after (January, $\mathrm{T}^{\circ} \mathrm{C}=11$ ) a 48 -h exposure to one of four experimental treatments (control, dispersant, oil alone and oil + dispersant mixture). During the period June-October (3-7 month post-exposure) fish were held in a field mesocosm to assess the effect of experimental treatments upon fish capacity to thrive under semi-natural conditions. During the entire experimental period, fish were submitted to the natural temperature $\left(9-20^{\circ} \mathrm{C}\right)$, photoperiod and salinity (30-32 PSU) seasonal cycles.

\subsection{Fish transport}

Experimental fish were transported between experimental sites in a $1 \mathrm{~m}^{3}$ covered tank. Fish were first anaesthetized (phenoxyethanol; $0.2 \mathrm{~mL} \mathrm{~L}^{-1}$ ) and transferred to the transport tank where a light dose of anaesthetic was added (phenoxyethanol; $0.05 \mathrm{~mL} \mathrm{~L}^{-1}$ ) to reduce stress. Water temperature (seasonal value) and oxygen level (> $95 \%$ air saturation) were monitored continuously during the journeys. 


\subsection{Challenge tests for functional indicators}

Hypoxia challenge tests and temperature challenge tests were performed in the rearing tank according to Claireaux et al. (2013). In these tests, fish from the four experimental treatments were tested in one single run.

\subsubsection{Hypoxia challenge test}

The hypoxia challenge test involved a rapid decrease of water oxygen level from around $100-20 \%$ air saturation over $1 \mathrm{~h}$, after which oxygen level was reduced at a much slower rate $\left(2 \%\right.$ decrease in air saturation $\left.\mathrm{h}^{-1}\right)$ until the experiment was terminated. Hypoxia was controlled by introducing nitrogen into the tank using a submersible pump. The water oxygen level was monitored using a calibrated oxygen meter (Odeon, Ponsel Mesure, France). As individual fish lost their ability to maintain equilibrium, they were quickly removed from the experimental arena, identified (tag reading) and placed in a fully aerated recovery tank. The corresponding time (time to loss of equilibrium; TLOE) and oxygen level (incipient lethal of oxygen saturation; ILOS) were also recorded.

\subsubsection{Temperature challenge test}

The temperature challenge test involved an initial rapid increase of water temperature (from ambient temperature to $27^{\circ} \mathrm{C}$ in typically $2.5 \mathrm{~h}$ ), after which temperature was increased more slowly $\left(0.5^{\circ} \mathrm{C} \mathrm{h}^{-1}\right)$ until the end of the experiment. Water temperature was controlled using two $3000 \mathrm{~W}$ heaters (Profi heater, Netherlands). A submersible pump (Eheim universal pump 2400, Germany) placed in the tank ensured thermal homogeneity. One hundred percent air saturation was 
maintained by bubbling a controlled mixture of oxygen and air in the tank. As individual fish lost their ability to maintain equilibrium, they were quickly removed from the experimental arena, identified (tag reading) and placed in a fully aerated recovery tank at the ambient temperature. The corresponding time (TLOE) and critical thermal maximum $\left(\mathrm{CT}_{\max }\right)$ were also recorded.

\subsubsection{Swimming challenge test}

The swimming challenge test employed a custom-made swimming flume comprising two translucent swimming chambers (length: $2 \mathrm{~m}$, diameter: $20 \mathrm{~cm}$ ). Water velocity in these swimming chambers was controlled using a pump (80/16-DE, Calpeda) connected to a frequency regulator (Mitsubishi, F700, Japan). During swimming trials water velocity was monitored continuously using a flow meter (HFA, Höntzsch $\mathrm{GmbH}$, Germany). Seawater was supplied to the swimming chambers from a tank containing thermoregulated and aerated water. Water flow in the swimming chambers was made laminar by passage through two honeycomb sections (length = $50 \mathrm{~cm}$ ) placed upstream from each swimming chamber.

Fish were swum in groups of approximately 60 individuals haphazardly dip-netted from the rearing tank. Following transfer into the swimming flume, fish were habituated for $3 \mathrm{~h}$ at slow water velocity $\left(8 \mathrm{~cm} \mathrm{~s}^{-1}\right)$ before the swimming trial was initiated. Swimming trials started by continuously increasing the water velocity from acclimation $\left(8 \mathrm{~cm} \mathrm{~s}^{-1}\right)$ to $40 \mathrm{~cm} \mathrm{~s}^{-1}$ over approximately $30 \mathrm{~min}$. Water velocity was then increased incrementally by $5 \mathrm{~cm} \mathrm{~s}^{-1}$ every 10 min until all the fish present in the chamber had reached exhaustion (typically $<120 \mathrm{~cm} \mathrm{~s}^{-1}$ ). Fish were considered to be exhausted when they would not remove themselves from the grid place downstream 
from the swim chamber. At that time, they were removed from the flume via a hatch situated above the back grid, identified and placed in a recovery tank. The corresponding time (time to exhaustion; TE) and water velocity were recorded. Maximal swimming speed ( $U_{\max }$; see Farrell, 2008) was calculated according to Brett (1964). No correction for potential blocking effect was applied.

One week was allowed for recovery between each of the above challenge tests. During these periods, no mortality was observed.

\subsection{Experimental exposure}

In March 2013, fish (mass: $21.0 \pm 0.2 \mathrm{~g}$, length: $12.16 \pm 0.03 \mathrm{~cm}$ ) were transported from Ifremer laboratory to the fish rearing facilities of the Centre of Documentation, Research and Experimentation on Accidental Water Pollution (CEDRE, Brest, France; $12 \mathrm{~km}$ ) where temperature, salinity, photoperiod and feeding conditions were identical to those previously described.

A set of 12 polyethylene tanks ( $300 \mathrm{~L}$ ) was used for fish exposure (Milinkovitch et al., 2011). Four experimental conditions were tested in triplicate (190 fish per condition, $\approx 60$ fish per replicate): control (CONT), $1 \mathrm{~g}$ of dispersant per $300 \mathrm{~L}$ (DISP), $25 \mathrm{~g}$ of oil per $300 \mathrm{~L}$ (OIL) and $1 \mathrm{~g}$ of dispersant plus $25 \mathrm{~g}$ of oil per $300 \mathrm{~L}$ (OIL + DISP). Before being used in the exposure set up, Arabian light crude oil was bubbled with air until its mass was reduced by approximately $10 \%$ to mimic a 12 -h ageing of an oil slick at sea (Nordvik, 1995). The oil concentration used in this study aimed to reproduce conditions encountered in the vicinity of an oil slick (Sammarco et al., 2013). The dispersant (Corexit $\AA$ EC9500A, Nalco) was used in accordance with the 
manufacturer's recommendation. Fish were allocated to the various exposure tanks in such a way that no statistically significant difference in $U_{\max }$, ILOS and CT $\max$ was found among the tanks.

Exposure tanks were equipped with a custom-made water mixing devices comprising a funnel and a $12 \mathrm{~V}$ submersible bilge pump (L450-500GPH; Johnson). These devices were adjusted in such a manner that any surface water and floating oil would be sucked into the funnel, homogenized and delivered to the bottom of the tank. During the 48-h exposure period, the water in the tanks was not renewed and aeration was maintained via air bubbling.

Following the 48-h exposure period, fish were bathed in clean seawater to remove any obvious oil contamination and transferred to their original rearing tank where they remained for one week before being transported back to Ifremer laboratory. Fish from the different treatments were identifiable (RFID-tag) and so they were mixed together in one common-garden 2 m3-tank where water and feeding conditions were similar to those described above. No mortality occurred during exposure and the following weeks.

To characterize the exposure conditions, water total petroleum hydrocarbon concentration was measured immediately before and 4, 24 and $48 \mathrm{~h}$ after fish introduction into the exposure tanks. Moreover, 9 fish per treatment were sacrificed to measure white muscle PAH concentrations at $48 \mathrm{~h}$ and 1 month post-exposure to confirm PAH initial uptake and subsequent elimination. 


\subsection{Chemical analyses}

Total petroleum hydrocarbon concentration ([TPH]) in each exposure tank was measured in triplicate with a seawater sample volume of $100 \mathrm{~mL}$ taken at $0,4,24$ and $48 \mathrm{~h}$ after the fish were introduced in the tank. The seawater samples were extracted 3 times using $10 \mathrm{~mL}$ of dichloromethane Pestipur quality (SDS, Carlo Erba Reagent, France) and the combined organic phases of the extracts were dried by filtering through anhydrous sodium sulfate (pesticide grade). The absorbance of the organic phase was measured using a spectrophotometer at $390 \mathrm{~nm}$ (Evolution 600 UV-VIS; Thermo Fisher Scientific) as described in Fusey and Oudot (1976).

The concentrations of 21 polycyclic aromatic hydrocarbons (PAH) (including US EPA compounds) in the white muscle samples taken at 48-h and 1-month post-exposure were assessed by gas chromatography-tandem mass spectrometry (GC-MS/MS) using a procedure described in Lacroix et al. (2014). PAH were extracted from muscles samples using alkaline digestion combined with stir-bar sorptive extraction (SBSE) before analysis by GC-MS/MS. Briefly, samples were individually crushed and $1 \mathrm{~g}$ wet weight of minced muscle was added to $10 \mathrm{~mL}$ of HPLC-grade anhydrous ethanol (Carlo Erba Reagents, France) containing 10 ng of 7 deuterated internal standards and $0.5 \mathrm{~g}\left(0.05 \mathrm{~g} \mathrm{~mL}^{-1}\right)$ of potassium hydroxide (analytical grade). Samples were subsequently digested for $3 \mathrm{~h}$ at $80^{\circ} \mathrm{C}$ in hermetic flasks. The digested samples were then cooled to room temperature before addition of $100 \mathrm{~mL}$ of reverse osmosis water. Polydimethylsiloxane stir-bars (Twister $20 \mathrm{~mm} \times 0.5 \mathrm{~mm}$, Gerstel, Germany) were then placed in the solutions and stirred at $700 \mathrm{rpm}$. After $2 \mathrm{~h}$ of extraction, stirbars were removed from solutions, rinsed with reverse osmosis water and dried over a blot paper. The stir-bars were stored at $-20{ }^{\circ} \mathrm{C}$ until GC-MS/MS analysis using 
agilent 7890A coupled to an Agilent 7000 Triple Quadrupole (Agilent, USA). Calibration solutions were obtained by dilutions (in ethanol) of a custom standard solution containing the analytes and provided by Ultra Scientific (USA). PAH levels were quantified relatively to deuterated PAH. Samples water content was determined after drying a sample aliquot for $48 \mathrm{~h}$ at $80^{\circ} \mathrm{C}$. Results were expressed as $\mathrm{ng} \mathrm{PAH} / \mathrm{g}$ dry weight.

\subsection{Field mesocosm exposure}

On May 31st 2013 i.e., approximately 3 months after the experimental exposures, fish ( $N=680,170$ per treatment) were transported to the "French National Center for Scientific Research (CNRS)" field station in L'Houmeau (450 km from Brest). L'Houmeau mesocosms have been described previously ( Nelson and Claireaux, 2005, Claireaux et al., 2007 and Handelsman et al., 2010). Briefly, 200-m2, 1-m deep earthen ponds are connected to the nearby ocean via a canal which allows partial seawater renewal with each incoming tide. A set of standpipes prevented fish from escaping. Moreover, netting placed above the ponds prevented avian predation. Previous experiments and empirical observations have shown that a natural food web develops in these ponds which can sustain $2-3 \mathrm{~kg}$ of fish. A complete description of these earthen pond's fauna can be found in de Montaudouin and Sauriau (2000). During the experiment, water conditions in the ponds were measured once a week between 11:00 and 14:00.

Immediately upon arrival at L'Houmeau field station, fish were distributed among 7 mesocosm ponds (96 fish per pond, i.e., 24 fish per treatment). To assess survivorship and growth, ponds were individually drained on July 11th, September 
9th and finally October 31st when all survivors $(N=470)$ were transported back to Brest and returned to their original rearing facility at the Ifremer laboratory.

\subsection{Data analysis and statistics}

The temporal stability of performance at challenge tests was tested using Spearman rank-order correlation between challenge tests set \#1 and \#2 (3-months repeatability) and between challenge tests set \#1 and \#3 (11-months repeatability). Total petroleum hydrocarbon concentration in water and $\mathrm{PAH}$ concentrations in white muscle were compared among exposure treatments using an ANOVA. In order to compare the performance at the challenge tests, a Kaplan-Meier survival analysis was conducted. Exposure effect was assessed using log-rank test with the HolmŠídák method for multiple comparisons. Fish survival in the ponds was analysed using the same procedure. Growth rate measured during the field experiment were analysed using a 2-way mixed ANOVA with pond defined as a random effect. Functional performance of the fish that died and fish that survived the mesocosm exposure were compared using an ANOVA. Values are presented as a mean \pm SEM and significance was accepted at $p<0.05$. All statistical analyses were performed using R (R Development Core Team, 2008) and SigmaPlot 13 (Ritme). 


\section{Results}

\subsection{Exposure conditions}

As expected, water total petroleum hydrocarbon concentration ([TPH]) in the control (CONT) and the dispersant-added (DISP) tanks were below the quantification limit (Fig. 2). On the other hand, [TPH] in the oil (OIL) and oil + dispersant (OIL + DISP) tanks were, respectively, 6- and 10-times higher than the quantification limit and they remained at that level throughout the exposure period.

Similarly, the white muscle tissue concentrations of 21 polycyclic aromatic hydrocarbon compounds ([21 PAH]) measured 2 days post-exposure in fish from the CONT and DISP treatments were below the quantification limit, while concentrations measured in fish from the OIL and OIL + DISP treatments were nearly 250-times that limit (Fig. 3). No significant difference in white muscle tissue [21 PAH] was observed between the OIL and OIL + DISP treatments (ANOVA; $p=0.2565$ ). At 1 month postexposure, white muscle [21 $\mathrm{PAH}]$ was below the quantification limit in all four treatments. It must be noted that among the 21 compounds measured, only four (naphthalene, fluorene, dibenzothiophene, phenanthrene) were above the quantification limit (Appendix A). At 1 month post-exposure, white muscle [21 PAH] was below the quantification limit in all four treatments.

\subsection{Repeatability of individual performance}

Individual performance of the CONT fish at the hypoxia challenge test (time to loss of equilibrium, TLOE) was repeatable when this challenge was repeated 3 and 11 months apart (Fig. 4A; $r_{s}=0.2931, p=0.0001$ and $r_{s}=0.2531, p=0.0437$ 
respectively). Similarly, swimming performance (time to reach exhaustion, TE) of the CONT group was stable over 3- and 11-month periods (Fig. 4C; $r_{s}=0.3652, p<$ 0.0001 and $r_{s}=0.2897, p=0.0392$, respectively). Critical temperature (time to loss of equilibrium, TLOE) of the CONT fish was also repeatable after 3 months (Fig. 4B; $\left.r_{s}=0.2178, p=0.0058\right)$, but not after 11 months $\left(r_{s}=0.1377, p=0.2742\right)$.

Performance stability over time of fish exposed to dispersant, oil alone or chemically treated oil are summarized in Fig. 4D. Performances of fish from the DISP treatment at hypoxia and temperature challenge test were repeatable or marginally repeatable when these challenges were repeated 3 -month apart $(p=0.0639$ and 0.0023$)$. However, performances were not stable over an 11-month period $(p=0.2089$ and 0.5927). Swimming performance of fish exposed to dispersant was stable over 3and 11-month periods ( $p<0.0001 ; 0.0116$ respectively). Concerning fish exposed to oil, individual performances at hypoxia and swimming challenge tests were repeatable over 3 - and 11-month periods $(p=0.0016 ;<0.0001$ and $0.0307 ; 0.0386$ respectively). Temperature susceptibility of these fish was stable over a 3 month period $(p=0.0034)$ but not over 11 months $(p=0.2054)$. Finally, fish from the OIL + DISP treatment displayed stable performance when hypoxia and swimming challenge tests were repeatable over a 3 -month period $(p=0.0035 ;<0.0001$, respectively). Performance repeatability of fish from this treatment at temperature challenge test was also marginally significant $(p=0.0681)$. However, performances of fish exposed to chemically dispersed oil at the three challenge tests were not stable over an 11-month period $(p>0.2)$. 


\subsection{Short-term effects of the treatments on fish performance}

Fish performance in the hypoxia challenge tests is summarized in Fig. 5A. Mean time to loss of equilibrium (TLOE) of the control fish was $9.2 \pm 0.03 \mathrm{~h}$, which corresponded to a mean ILOS of $4.00 \pm 0.06 \%$ air saturation. No significant difference with the DISP and OIL treatments was observed (Log-rank; $p=0.33$ and 0.13 , respectively). However, the OIL + DISP fish were significantly less tolerant to hypoxia than the CONT group with a mean TLOE of $9.10 \pm 0.02 \mathrm{~h}$ (i.e., mean ILOS $=4.22 \pm 0.05 \%$ air saturation; $p=0.007)$.

During the temperature challenge test (Fig. 5B), CONT fish mean TLOE was $9.16 \pm$ $0.07 \mathrm{~h}$, which corresponded to a mean $\mathrm{CT}_{\max }$ of $32.50 \pm 0.04{ }^{\circ} \mathrm{C}$. Again, no significant difference with DISP, OIL and OIL + DISP treatments was observed (Log-rank; $p=$ $0.34)$

For the swimming challenge test (Fig. 5.C), CONT mean time to exhaustion (TE) was $1.84 \pm 0.03 \mathrm{~h}$, which corresponded to a swimming velocity $\left(\mathrm{U}_{\max }\right)$ of $80.4 \pm 0.8 \mathrm{~cm} \mathrm{~s}^{-1}$. No significant difference was observed with the DISP and OIL treatments (Log-rank; $p=0.85$ and $p=0.17$ respectively). However, the OIL + DISP fish had a significantly lower swimming performance than the CONT group (TE $=1.72 \pm 0.02 \mathrm{~h} ; \mathrm{U}_{\max }=77.7$ $\pm 0.6 \mathrm{~cm} \mathrm{~s}^{-1} ;$ Log-rank; $\mathrm{p}=0.008$ ).

\subsection{Field mesocosm study}

Water conditions in the earthen ponds over the 5-month field experiment are summarized in Fig. 6. The observed fluctuations in water temperature are typical of this type of ecosystem, temperature being the lowest in early June $\left(15.8^{\circ} \mathrm{C}\right)$ and the 
highest at the end of July $\left(25.1^{\circ} \mathrm{C}\right)$. Salinity also fluctuated from a low of $30.8 \%$ in early June to a high of $40.0 \%$ in late August. Water oxygen content varied between 8 and $10 \mathrm{mg} \mathrm{L}^{-1}$ during most of the field experiment, except in early August when values as low as $4.6 \mathrm{mg} \mathrm{L}^{-1}$ were measured. Water $\mathrm{pH}$ fluctuated within a broad range i.e., 7.5-8.7. All variables considered, August was possibly the most challenging period when high temperature coincided with high salinity, low oxygenation and low $\mathrm{pH}$.

Sea bass growth varied over the 5-month period, but no statistically significant difference was observed among the ponds (ANOVA; $p<0.001$ and $p=0.12$, respectively) (Fig. 7A). The summer period (July-August) was associated with best growth. During autumn (September-October), fish growth was markedly suppressed, with fish from ponds 2, 4 and 7 even losing weight. No difference between experimental treatments was noted (ANOVA; $p=0.90)$ (Fig. 7B).

Survivorship was $>60 \%$ at the end of the field experiment and no statistically significant difference was observed among experimental treatments $(p=0.63$; data not shown).

Hypoxia tolerance, susceptibility to heat and swimming capacity of the fish that survived the field mesocosm were compared to those of the fish that died (Fig. 8). To make this comparison we used the challenge tests conducted just before fish were transferred to the mesocosms, i.e., 1-month post-exposure. Fish that died during the spring and summer periods had swimming performance, hypoxia tolerance and thermal susceptibility that were not statistically different from those of the fish that 
survived (swimming TE: spring $1.82 \pm 0.02$ vs $1.78 \pm 0.03$, summer $1.81 \pm 0.02$ vs $1.92 \pm 0.12 ;$ hypoxia TLOE: spring $9.15 \pm 0.01$ vs $9.11 \pm 0.03$, summer $9.15 \pm 0.02$ vs $9.16 \pm 0.05$; temperature TLOE: spring $9.02 \pm 0.04$ vs $9.09 \pm 0.10$, summer $9.02 \pm$ 0.04 vs $8.98 \pm 0.14)$. During the autumn, on the other hand, fish that did not survive had a lower hypoxia tolerance and lower swimming performance than fish that did survived (swimming TE: $1.82 \pm 0.02$ vs $1.69 \pm 0.04$; hypoxia TLOE: $9.17 \pm 0.01$ vs $9.05 \pm 0.04$ ). No difference in thermal tolerance was, however, observed (TLOE: 9.00 \pm 0.05 vs $9.16 \pm 0.11$ )

\subsection{Long-term effects of the treatments and validation of the field observations}

Approximately 10 months post-exposure and 4 months after the survivors (460 fish) had returned from the field mesocosm, the suite of challenge tests was repeated. No significant differences were observed among the four treatments (Log-rank; hypoxia challenge test: $p=0.760$; temperature challenge test: $p=0.232$; swimming challenge test: $p=0.295$ ). Mean time to loss of equilibrium of the control fish was $7.89 \pm 0.08 \mathrm{~h}$ $\left(2.3 \pm 0.1 \%\right.$ air saturation) for the hypoxia challenge test and $5.23 \pm 0.13 \mathrm{~h}\left(\mathrm{CT}_{\max }\right.$ : $28.12 \pm 0.09^{\circ} \mathrm{C}$ ) for the temperature challenge test. Mean time to exhaustion for the swimming challenge test was $1.22 \pm 0.05 \mathrm{~h}\left(\cup_{\max }: 62.6 \pm 1.5 \mathrm{~cm} \mathrm{~s}^{-1}\right)$.

\section{Discussion}

Using the chemical treatment of an oil spill and an acute exposure scenario as a case study, this experiment aimed at testing a methodology to evaluate the health status of a fish population following a toxicological insult. We used incipient lethal oxygen saturation (ILOS), critical thermal maximum ( $\left.\mathrm{CT}_{\max }\right)$ and maximal swimming 
speed $\left(\cup_{\max }\right)$ as markers of fish ability to cope with natural contingencies, and based on the definition given for humans, we considered that they were proper indicators of fish health. The suite of challenge tests showed that 1 month after exposure, fish from the dispersant alone and oil alone treatments displayed no functional impairments, while fish exposed to chemically dispersed oil had residual effects of reduced hypoxia tolerance and swimming capacity. Transfer of our experimental populations to the field revealed that, under selective feeding condition (autumn), predetermined swimming performance and hypoxia tolerance were higher in individuals that survived than in individuals that did not, validating the ecological relevance of these biomarkers. However, values of thermal susceptibility were not predictors of individuals' survival during our mesocosm experiment. No difference in field survival and growth was observed among the experimental treatments, suggesting that recovery had occurred at the whole animal level. Correspondingly, when hypoxia tolerance, temperature susceptibility and swimming performance were tested 10 months post-exposure i.e., as surviving fish were returned from the field site into the laboratory, no difference among the treatments was observed, confirming that they had recovered from the functional impairments observed one month post-exposure.

\subsection{Exposure conditions and white muscle [21 PAH]}

Water concentration in total petroleum hydrocarbon ([TPH]) was monitored in all tanks and throughout fish exposure period in order to characterize the exposure conditions and ensure that they were realistic. Mean $[\mathrm{TPH}]$ in the oil and oil + dispersant exposure tanks $\left(28.5 \pm 5.0\right.$ and $49.4 \pm 2.3 \mathrm{mg} \mathrm{L}^{-1}$ respectively $)$ corresponded to concentrations reported following oil spills such as Tarut Bay (Saudi 
Arabia, 1970), Hebei Spirit (South Korea, 2007) and Deepwater Horizon (USA, 2010) (1-750 mg L-1; Spooner, 1970, Kim et al., 2010 and Sammarco et al., 2013). Moreover, the $30 \%$ higher [TPH] measured in the oil + dispersant exposure tanks compared to the oil-alone tanks, indicated that dispersant increased the potential bioavailability of the oil components (Ramachandran et al., 2004).

Polycyclic aromatic hydrocarbon concentrations ([21 PAH]) were measured in fish white muscle 2 days and 1 month post-exposure, the latter corresponding to a few days before the second suite of challenge tests was conducted. Two days postexposure, fish from the control and dispersant treatments displayed white muscle [21 $\mathrm{PAH}$ ] below the quantification limits (1 $\mathrm{ng} \mathrm{g}^{-1}$ dry weight). On the other hand, fish from the oil and chemically dispersed oil treatments displayed white muscle [21 $\mathrm{PAH}$ ] considerably in excess of the quantification limit $\left(253 \pm 20\right.$ and $224 \pm 11 \mathrm{ng} \mathrm{g}^{-1}$ dry weight, respectively). It must be emphasised, however, that fish can rapidly metabolize PAH and so the muscle tissue samples from 2 days post-exposure may underestimate maximal white muscle PAH concentration (Hellou and Warren, 1997 and Varanasi, 1989; Dussauze et al., 2015). Nevertheless, these concentrations are very similar to those measured in the white muscles of the rockfish (Sebastes schlegeli) 5 days following the Hebei Spirit oil spill (284 $\mathrm{ng} \mathrm{g}^{-1}$ dry weight; Jung et al., 2011) and are in line with a previous experiment that investigated similar oil exposure conditions (148 $\pm 46 \mathrm{ng} \mathrm{g}^{-1}$ dry weight; Danion et al., 2011). A closer look to individual $\mathrm{PAH}$ concentrations in fish muscle reveals that tricyclic PAH (fluorene, dibenzothiophene, phenanthrene) represent approximately $98 \%$ of the total $[\mathrm{PAH}]$. This is attributable to the weathering process, which is recognized to bring a shift in PAH composition. The fraction of the tricyclic PAH within the total dissolved PAH 
measured in water indeed increase relative to the smaller two-rings compounds when spilled oil is weathered ( Carls et al., 1999, Heintz et al., 1999 and Short and Heintz, 1997). One month after exposure, white muscle [21 PAH] concentrations in all four experimental treatments had been restored to a background level.

\subsection{Repeatability of individual's performance}

In order to assess our capacity to standardize the testing protocols, and to demonstrate the ecological relevance of our markers of functional integrity, the longterm temporal stability ( 3 and 11 months) of the hypoxia tolerance, temperature susceptibility and swimming performance was examined. In the control group, we observed that time to loss of equilibrium (TLOE) at the hypoxia challenge test and time to reach exhaustion (TE) at the swimming challenge test were both repeatable after 3-month and 11-month periods, whereas TLOE at the temperature susceptibility challenge test was repeatable after a 3 -month period but not after 11 months. This observation validates our capacity to standardize the challenge tests. Short-term temporal stability of fish swimming performance has been documented by several authors including Kolok (1992 and Claireaux et al. (2007. Moreover, an earlier study by Claireaux et al. (2013) documented the 2-month repeatability of hypoxia and heat tolerance in sea bass. This temporal stability under changing environmental conditions, combined with the fact that hypoxia tolerance, temperature susceptibility and swimming performance have been shown to be heritable (Garenc et al., 1998 and Anttila et al., 2013), substantiate the view that these traits are potential targets for natural selection (Hayes and Jenkins, 1997 and Dohm, 2002). It is important to note that Spearman's rank correlation coefficients were lower when considering performance measured 11 months apart than those measured 3 months apart. This 
suggests a progressive loss of repeatability over time. This observation is explained by the fact that this study was conducted using juveniles. Growth and ageing, and associated rearranging of phenotypic architecture, are processes that are likely to blur repeatability (Killen et al., 2016). Moreover, the 11-month period includes the field experiment during which fish were submitted to a large variety of conditions including a major change in food source. This is liable to affect intra-population variability and, potentially, the degree to which our targeted performances remain stable over time (Killen et al., 2016).

The effect of exposure to dispersant, oil alone or a mixture of both upon individual performances temporal stability was also examined. We observed that repeatability over a 3-month period was maintained in all the four treatments. On the other hand, performances measured 11-months apart were not necessarily repeatable. It is important to note, however, that this loss of repeatability is not readily attributable to the exposure treatments as several confounding factors including ageing, sexual maturation, growth and change in environmental conditions may have contributed in modifying the phenotypic architecture within our experimental populations (Killen et al., 2016).

\subsection{One-month post-exposure functional tests}

At one month post-exposure, performance in the hypoxia challenge test of the dispersant-exposed fish was not statistically different from that of the control fish. This result is in line with Claireaux et al. (2013), who reported no effect of dispersant alone (Finasol@ OSR-52) on fish hypoxia tolerance. Hypoxia tolerance of fish from the oil alone treatment also was not statistically different from that of the control fish. 
This result of juvenile sea bass to Arabian light crude $\left(\mathrm{CAL} ;[\mathrm{TPH}]=56 \pm 5.2 \mathrm{mg} \mathrm{L}^{-1}\right)$. is, however, not in line with Davoodi and Claireaux (2007), who reported reduced hypoxia tolerance in juveniles of the common sole (Solea solea). In this latter study, however, sole were exposed to a dose of No-2 fuel which was approximately 50times higher than in the present study $\left(4 \mathrm{~g} \mathrm{~L}^{-1}\right.$ vs $\left.0.08 \mathrm{~g} \mathrm{~L}^{-1}\right)$.

In our experiment, the deleterious effect of oil exposure on seabass hypoxia tolerance was only revealed in the OIL + DISP treatment, as the increase in water $[\mathrm{TPH}]$ induced by the dispersant was associated with reduced ILOS. This observation confirmed that dispersant reinforces the effect of oil in the short term (Ramachandran et al., 2004 and Anderson et al., 2009). The few studies that have examined the impact of oil exposure upon hypoxia tolerance suggest a relationship via altered cardio-respiratory function (Claireaux et al., 2004 and Davoodi and Claireaux, 2007). This hypothesis is consistent with established histomorphological alterations to the gills, leading to reduced oxygen diffusion across the respiratory epithelium and into the vascular system (McKeown and March, 1978 and Engelhardt et al., 1981).

Thermal tolerance of fish from the DISP, OIL and OIL + DISP treatments were not statistically different from fish from the control group. This is in line with Claireaux et al. (2013), who reported no effect of the same exposure conditions upon sea bass temperature susceptibility 4 weeks post-exposure. The underlying mechanisms to temperature susceptibility remain unclear (Beitinger and Lutterschmidt, 2011; Schulte, 2015). However, the oxygen and capacity limited thermal tolerance (OCLTT) theory, even if still debated, suggests that functional integrity at high temperature may be limited by a mismatch between tissues oxygen demand and the capacity of 
the cardiovascular system to supply them with oxygen (Pörtner and Knust, 2007). Cardiac function is central to both hypoxia and heat tolerance and one could have expected a correlation between an individual's ILOS and $C T_{\max }$. The fact that we did not find such correlation (data not shown) suggests that other functions and processes are involved in shaping inter-individual variability in these performance traits, e.g., energy metabolism, anaerobic pathways, oxygen extraction and diffusion at the gill, sensitivity of the central nervous system to anaerobic metabolism byproducts ( Shoubridge and Hochachka, 1980, Hochachka and Somero, 2002 and Nilsson and Östlund-Nilsson, 2008). The lack of relationship between ILOS and $\mathrm{CT}_{\max }$ could also result from the ILOS measuring principle. Incipient lethal oxygen saturation determination is indeed based on exposing fish to an oxygen level which is far below sea bass critical oxygen level $\left(20 \%\right.$ of air saturation at $\left.15^{\circ} \mathrm{C}\right)$. Therefore, ILOS may be an index which reflects fish anaerobic capacities (Claireaux and Chabot, 2016), while heat tolerance rather reflects oxygen uptake and transport capacities.

Swimming performance of fish exposed to either dispersant or oil alone did not differ from the control. This result is in line with McKenzie et al. (2007), who showed that carp (Cyprinus carpio) caged for 3 weeks in sites heavily polluted with cocktails of bioavailable organics including $\mathrm{PAH}(12.4 \mu \mathrm{g}$ of $\mathrm{PAH}$ collected on semipermeable membrane) displayed similar swimming capacity as fish from a control, unpolluted site. Our findings are, however, contradictory with Kennedy and Farrell (2006) who reported a $25 \%$ decrease in the maximal swimming speed of the Pacific herring (Clupea pallasi) 8 weeks after a 4-day exposure to the water-soluble fraction (WSF) of North Slope crude oil $\left([\mathrm{TPH}]=120 \mu \mathrm{g} \mathrm{L}^{-1}\right)$. Likewise, Oliveira et al. (2012) reported 
reduced swimming performance immediately after a 96-h exposure to pyrene (concentrations ranging from 0.125 to $1 \mathrm{mg} \mathrm{L}^{-1}$ ). Thomas and Rice (1987) also reported a $12 \%$ decrease in swimming performance of juvenile coho salmon (Oncorhynchus kisutch) within hours of a 48-h exposure to the WSF of Cook Inlet crude oil [ $\left.>2.5 \mathrm{mg} \mathrm{L}^{-1}\right]$. The detrimental effect of hydrocarbon exposure upon fish swimming performance was confirmed by our observation that chemically treated oil treatment impaired sea bass capacity to swim maximally. This strengthens the view that, although not directly affecting fish performance, dispersants potentiate oil toxicity. The mechanisms by which petroleum hydrocarbon exposure might affect swimming capacity are largely unknown as a large set of physiological processes are potentially involved. It has been shown, for instance, that swimming capacity is sensitive to changes in maximal aerobic capacity, cardiac output, function of red and white muscle fibers, as well as anaerobic metabolism ( Farlinger and Beamish, 1977, Beamish, 1978, Thorarensen et al., 1996, Alsop and Wood, 1997 and Burgetz et al., 1998). Impaired swimming performance may also be the result of the aerobic cost of the detoxification, resulting in reduced scope for activity (Beamish, 1978, Alsop and Wood, 1997 and Gregory and Wood, 1999). Although not specifically examined here, gill damage caused by oil exposure ( McKeown and March, 1978, Engelhardt et al., 1981, Khan, 2003 and Simonato et al., 2008) could also result in impaired oxygen delivery tissues during swimming exercise.

\subsection{Field observations}

The field study aimed to ascertain the link between performance in the challenge tests and components of Darwinian fitness, by establishing whether the functional impairments observed shortly after exposure had some subsequent ecological 
relevance under natural conditions. Water conditions observed in the experimental mesocosms during spring, summer and autumn were in accordance with previous observations (Claireaux et al., 2013). With the noticeable exception of water $\mathrm{pH}$, low inter-pond variability in water conditions was observed. We have no satisfactory explanation for the marked among-ponds variability in water $\mathrm{pH}$, but combined with observations of ponds' vegetal groundcover, it points towards variability in pond ecology, with possible consequences in terms of qualitative and quantitative food availability.

Compared with previous studies, the observed fish survival rate was high overall $(>60 \%)$. For instance, preceding work using the same field site yielded survival rates ranging between 20 and $30 \%$ (Claireaux et al., 2013). As might be expected, these remarkable survival records during spring and summer were associated with the highest growth rates, which ranged between 0.10 and $0.20 \% \mathrm{~d}^{-1}$ (Fig. 7a). These growth rates are indeed remarkable if one considers that the growth rate of sea bass under food unlimited, farming conditions is $0.25 \% \mathrm{~d}^{-1}$ (Guillaume, 2001).

Despite favourable environmental and feeding conditions, mortality still occurred during spring (16\%) and summer (5\%). Examination of the predetermined performances at the challenge tests did not allow a conclusion concerning a possible link with survivorship during these periods. This suggests that, at least during the spring period, the relatively higher mortality recorded possibly resulted from the inability of certain individuals to acclimate following the transfer from the lab to the field. In September-October, on the other hand, food availability decreased and competition for food became selective, as illustrated by the nearly $90 \%$ reduction in 
growth rate observed during that period. Interestingly, fish that died during that period (mortality 12\%) displayed lower swimming performance, suggesting that high swimming capacity to capture scarce prey was key to survival. More intriguing is the observation that non-survivors also displayed lower tolerance to hypoxia than survivors. During autumn, oxygenation conditions were optimal and they cannot be considered as a direct source of selective mortality (Fig. 6). Alternatively, it can be hypothesized that the fact that fish that died were less tolerant to hypoxia than fish that survived resulted from a potential link between hypoxia tolerance, routine metabolic rate and starvation tolerance. Dupont-Prinet et al. (2010) investigated the link between tolerance of food deprivation, metabolic rate and growth rate in the European sea bass. They found that fast growing animals were also less tolerant to starvation than the slow growing individuals. However, contrary to the above functional hypothesis, these authors found no difference in routine metabolic rate between the starvation-tolerant and the starvation-sensitive phenotypes. Deciphering the functional basis of the relationship between environmental conditions, growth and survivorship clearly requires further study.

No significant difference in survivorship and growth was observed among the four exposure treatments, even during the period when natural selection was potentially the strongest (September-October). This result suggests that fish recovered from the impairments observed one month after exposure and that no long-term loss in individual fitness occurred in relation with exposure to either dispersant, oil and oil + dispersant mixture. 


\subsection{Eleven-month post-exposure challenge tests}

The motive for the long-term assessment conducted in this study was to verify whether the functional impairments observed shortly after exposure were long lasting. The fact that we observed no significant difference in fish performance 10 months post-exposure is remarkable and cannot be attributed to selective mortality during the field phase of the experiment as survivorship was in excess of $60 \%$. Moreover, a reanalysis of our challenge test data, excluding fish that died in the field, confirmed the effect of chemically dispersed oil observed one month post-exposure (hypoxia challenge test: $p=0.036$; swimming challenge test: $p=0.0009$ ) and that the lack of treatment-related effects observed 10-month post-exposure resulted from individuals recovering and not, for instance, from the culling of the most intoxicated ones during the field stage.

\section{Conclusion}

The main purpose of the research was to design and validate an ecologically relevant fish health assessment approach that could be applied to an acute toxicological exposure. Even though mild selective pressure was observed during the field exposure, hypoxia tolerance and maximal swimming speed measured in the laboratory were found to be predictors of survival. These results suggest that this methodology is liable to bridge the gap between sub-organismal toxicological disturbances and effects at population level.

We applied our health assessment methodology to a case of an acute oil exposure. Our study highlighted that exposure to dispersant and to oil alone does not affect fish health. Exposure to the oil and dispersant mixture was associated with temporarily 
impaired health. However, recovery occurred and no ecologically relevant consequences where observed when fish were transferred to a semi-natural field mesocosm. Fish health recovery was confirmed by the absence of long-term effects (almost 1 year post-exposure). We suggest that health-centred approach should be promoted and conducted using more fish species, life stages and environmental contexts in order to develop even further the notion of fish health. Such development would allow bridging the gap between toxicology and ecology and should prove highly valuable for the future safeguarding of the marine environment and the development of legislation for an integrated management of marine resources and services. 


\section{Acknowledgements}

Authors would like to thank M. Hervy (Aquativ), for providing us with the fish, as well as M. Prineau (LIENSS, UMR 7266), N. Le Bayon, O. Mouchel, P. Quazuguel, D. Mazurais, C. Huelvant, Y. Lemonnier, L. Cadiz (Ifremer), A. Leroy, P. Quéau (Cedre) and $\mathrm{H}$. Ollivier (UBO) for their technical assistance. This research was funded through ITOPF R\&D award 2012. It also received the financial support of TotalFluides. APF holds a Canada Research Chair. 


\section{References}

Alsop, D., Wood, C., 1997. The interactive effects of feeding and exercise on oxygen consumption, swimming performance and protein usage in juvenile rainbow trout (Oncorhynchus mykiss). Journal of Experimental Biology 200, 2337-2346.

Anderson, B.S., Arenella-Parkerson, D., Phillips, B.M., Tjeerdema, R.S., Crane, D., 2009. Preliminary investigation of the effects of dispersed Prudhoe Bay Crude Oil on developing topsmelt embryos, Atherinops affinis. Environmental Pollution 157, 1058-1061. doi:10.1016/j.envpol.2008.10.013

Anttila, K., Dhillon, R.S., Boulding, E.G., Farrell, A.P., Glebe, B.D., Elliott, J.A.K., Wolters, W.R., Schulte, P.M., 2013. Variation in temperature tolerance among families of Atlantic salmon (Salmo salar) is associated with hypoxia tolerance, ventricle size and myoglobin level. J Exp Biol 216, 1183-1190. doi:10.1242/jeb.080556

Beamish, F.W.H., 1978. Swimming capacity. Pages. 101-172 in WS Hoar and DJ Randall, editors. Fish physiology 7.

Beitinger, T.L., Lutterschmidt, W.I., 2011. TEMPERATURE | Measures of Thermal Tolerance, in: Encyclopedia of Fish Physiology. Elsevier, pp. 1695-1702.

Brander, S., Hecht, S., Kuivila, K., 2015. The Challenge: "Bridging the gap" with fish: Advances in assessing exposure and effects across biological scales. Environ Toxicol Chem 34, 459459. doi:10.1002/etc. 2829

Brett, J.R., 1964. The respiratory metabolism and swimming performance of young sockeye salmon. Journal of the Fisheries Board of Canada 21, 1183-1226.

Burgetz, I.J., Rojas-Vargas, A., Hinch, S.G., Randall, D.J., 1998. Initial recruitment of anaerobic metabolism during sub-maximal swimming in rainbow trout (Oncorhynchus mykiss). Journal of Experimental Biology 201, 2711-2721.

Carls, M.G., Rice, S.D., Hose, J.E., 1999. Sensitivity of fish embryos to weathered crude oil: Part I. Low-level exposure during incubation causes malformations, genetic damage, and mortality in larval pacific herring (Clupea pallasi). Environmental Toxicology and Chemistry 18, 481493.

Castro, V., Grisdale-Helland, B., Jørgensen, S.M., Helgerud, J., Claireaux, G., Farrell, A.P., Krasnov, A., Helland, S.J., Takle, H., 2013. Disease resistance is related to inherent swimming performance in Atlantic salmon. BMC Physiology 13, 1. doi:10.1186/1472-679313-1

Claireaux, G., Chabot, D., 2016. Responses by fishes to environmental hypoxia: integration through Fry's concept of aerobic metabolic scope. Journal of fish biology 88, 232-251.

Claireaux, G., Désaunay, Y., Akcha, F., Aupérin, B., Bocquené, G., Budzinski, H., Cravedi, J.-P., Davoodi, F., Galois, R., Gilliers, C., Goanvec, C., Guérault, D., Imbert, N., Mazéas, O., Nonnotte, G., Nonnotte, L., Prunet, P., Sébert, P., Vettier, A., 2004. Influence of oil exposure on the physiology and ecology of the common sole Solea solea: Experimental and field approaches. Aquatic Living Resources 17, 335-351. doi:10.1051/alr:2004043

Claireaux, G., Handelsman, C., Standen, E., Nelson, J.A., 2007. Thermal and Temporal Stability of Swimming Performance in the European Sea Bass. Physiological and Biochemical Zoology 80, 186-196. doi:10.1086/511143

Claireaux, G., McKenzie, D.J., Genge, A.G., Chatelier, A., Aubin, J., Farrell, A.P., 2005. Linking swimming performance, cardiac pumping ability and cardiac anatomy in rainbow trout. Journal of Experimental Biology 208, 1775-1784. doi:10.1242/jeb.01587

Claireaux, G., Théron, M., Prineau, M., Dussauze, M., Merlin, F.-X., Le Floch, S., 2013. Effects of oil exposure and dispersant use upon environmental adaptation performance and fitness in the European sea bass, Dicentrarchus labrax. Aquatic Toxicology 130-131, 160-170. doi:10.1016/j.aquatox.2013.01.004 
Danion, M., Le Floch, S., Lamour, F., Guyomarch, J., Quentel, C., 2011. Bioconcentration and immunotoxicity of an experimental oil spill in European sea bass (Dicentrarchus labrax L.). Ecotoxicology and Environmental Safety 74, 2167-2174. doi:10.1016/j.ecoenv.2011.07.021

Davoodi, F., Claireaux, G., 2007. Effects of exposure to petroleum hydrocarbons upon the metabolism of the common sole Solea solea. Marine Pollution Bulletin 54, 928-934. doi:10.1016/j.marpolbul.2007.03.004

Deem, S.L., Karesh, W.B., Weisman, W., 2001. Putting Theory into Practice: Wildlife Health in Conservation. Conservation Biology 15, 1224-1233. doi:10.1111/j.1523-1739.2001.00336.x

de Montaudouin, X., Sauriau, P.-G., 2000. Contribution to a synopsis of marine species richness in the Pertuis Charentais Sea with new insights in soft-bottom macrofauna of the MarennesOléron Bay. CBM-Cahiers de Biologie Marine 41, 181-222.

Dohm, M.R., 2002. Repeatability estimates do not always set an upper limit to heritability. Functional Ecology 16, 273-280. doi:10.1046/j.1365-2435.2002.00621.x

Dupont-Prinet, A., Chatain, B., Grima, L., Vandeputte, M., Claireaux, G., McKenzie, D.J., 2010. Physiological mechanisms underlying a trade-off between growth rate and tolerance of feed deprivation in the European sea bass (Dicentrarchus labrax). J Exp Biol 213, 1143-1152. doi:10.1242/jeb.037812

Dussauze, M., Danion, M., Floch, S.L., Lemaire, P., Theron, M., Pichavant-Rafini, K., 2015. Growth and immune system performance to assess the effect of dispersed oil on juvenile sea bass (Dicentrarchus labrax). Ecotoxicology and Environmental Safety 120, 215-222. doi:10.1016/j.ecoenv.2015.05.018

Engelhardt, F.R., Wong, M.P., Duey, M.E., 1981. Hydromineral balance and gill morphology in rainbow trout Salmo gairdneri, acclimated to fresh and sea water. As affected by petroleum exposure. Aquatic Toxicology 1, 175-186. doi:10.1016/0166-445X(81)90013-8

Farlinger, S., Beamish, F.W.H., 1977. Effects of time and velocity increments on the critical swimming speed of largemouth bass (Micropterus salmoides). Transactions of the American Fisheries Society 106, 436-439.

Farrell, A.P., 2008. Comparisons of swimming performance in rainbow trout using constant acceleration and critical swimming speed tests. Journal of Fish Biology 72, 693-710. doi:10.1111/j.1095-8649.2007.01759.x

Fry, F.E.J., 1947. Effects of the environment on animal activity. Toronto, University of Toronto Press.

Fusey, P., Oudot, J., 1976. Comparaison de deux méthodes d'évaluation de la biodégradation des hydrocarbures in vitro. Material und Organismen 241-251.

Garenc, C., Silversides, F.G., Guderley, H., 1998. Burst swimming and its enzymatic correlates in the threespine stickleback (Gasterosteus aculeatus): full-sib heritabilities. Can. J. Zool. 76, 680-688. doi:10.1139/z97-236

Gregory, T.R., Wood, C.M., 1999. The effects of chronic plasma cortisol elevation on the feeding behaviour, growth, competitive ability, and swimming performance of juvenile rainbow trout. Physiological and Biochemical Zoology 72, 286-295.

Guillaume, J., 2001. Nutrition and feeding of fish and crustaceans. Springer Science \& Business Media.

Handelsman, C., Claireaux, G., Nelson, J.A., 2010. Swimming Ability and Ecological Performance of Cultured and Wild European Sea Bass ( Dicentrarchus labrax ) in Coastal Tidal Ponds. Physiological and Biochemical Zoology 83, 435-445. doi:10.1086/651099

Hanisch, S.L., Riley, S.J., Nelson, M.P., 2012. Promoting wildlife health or fighting wildlife disease: Insights from History, Philosophy, and Science. Wildlife Society Bulletin 36, $477-$ 482. doi:10.1002/wsb. 163

Hayes, J.P., Jenkins, S.H., 1997. Individual Variation in Mammals. Journal of Mammalogy 78, 274-293. doi:10.2307/1382882 
Heintz, R.A., Short, J.W., Rice, S.D., 1999. Sensitivity of fish embryos to weathered crude oil: Part II. Increased mortality of pink salmon (Oncorhynchus gorbuscha) embryos incubating downstream from weathered Exxon Valdez crude oil. Environmental Toxicology and Chemistry 18, 494-503.

Hellou, J., Warren, W.G., 1997. Polycyclic aromatic compounds and saturated hydrocarbons in tissues of flatfish: Insight on environmental exposure. Marine Environmental Research 43, 11-25. doi:10.1016/0141-1136(95)00027-5

Hertzman, C., Power, C., Matthews, S., Manor, O., 2001. Using an interactive framework of society and lifecourse to explain self-rated health in early adulthood. Social Science \& Medicine 53, 1575-1585. doi:10.1016/S0277-9536(00)00437-8

Hochachka, P.W., Somero, G.N., 2002. Biochemical adaptation. Mechanisms and processes in physiological evolution. Oxford University Press, Oxford, UK.

Jung, J.-H., Kim, M., Yim, U.H., Ha, S.Y., An, J.G., Won, J.H., Han, G.M., Kim, N.S., Addison, R.F., Shim, W.J., 2011. Biomarker responses in pelagic and benthic fish over 1 year following the Hebei Spirit oil spill (Taean, Korea). Marine Pollution Bulletin 62, 1859-1866. doi:10.1016/j.marpolbul.2011.04.045

Kennedy, C.J., Farrell, A.P., 2006. Effects of exposure to the water-soluble fraction of crude oil on the swimming performance and the metabolic and ionic recovery postexercise in Pacific herring (Clupea pallasi). Environmental Toxicology and Chemistry 25, 2715-2724. doi:10.1897/05-504R.1

Khan, R.A., 2003. Health of flatfish from localities in Placentia Bay, Newfoundland, contaminated with petroleum and PCBs. Archives of Environmental Contamination and Toxicology 44, 0485-0492.

Killen, S.S., Adriaenssens, B., Marras, S., Claireaux, G., Cooke, S.J., 2016. Context dependency of trait repeatability and its relevance for management and conservation of fish populations. Conservation Physiology 4, cow007.

Kim, M., Yim, U.H., Hong, S.H., Jung, J.-H., Choi, H.-W., An, J., Won, J., Shim, W.J., 2010. Hebei Spirit oil spill monitored on site by fluorometric detection of residual oil in coastal waters off Taean, Korea. Marine Pollution Bulletin 60, 383-389. doi:10.1016/j.marpolbul.2009.10.015

Kolok, A.S., 1992. Short communication: the swimming performances of individual largemouth bass (Micropterus salmoides) are repeatable. J exp Biol 170, 265-270.

Lacroix, C., Le Cuff, N., Receveur, J., Moraga, D., Auffret, M., Guyomarch, J., 2014. Development of an innovative and "green" stir bar sorptive extraction-thermal desorptiongas chromatography-tandem mass spectrometry method for quantification of polycyclic aromatic hydrocarbons in marine biota. Journal of Chromatography A 1349, 1-10. doi:10.1016/j.chroma.2014.04.094

Marine and Coastal Ecosystems and Human Well-Being: Synthesis, 2006. . United Nations Publications.

McKenzie, D.J., Garofalo, E., Winter, M.J., Ceradini, S., Verweij, F., Day, N., Hayes, R., Oost, R. van der, Butler, P.J., Chipman, J.K., Taylor, E.W., 2007. Complex physiological traits as biomarkers of the sub-lethal toxicological effects of pollutant exposure in fishes. Phil. Trans. R. Soc. B 362, 2043-2059. doi:10.1098/rstb.2007.2100

McKeown, B.A., March, G.L., 1978. The acute effect of bunker C oil and an oil dispersant on: 1 Serum glucose, serum sodium and gill morphology in both freshwater and seawater acclimated rainbow trout (Salmo gairdneri). Water Research 12, 157-163.

Milinkovitch, T., Godefroy, J., Théron, M., Thomas-Guyon, H., 2011. Toxicity of dispersant application: biomarkers responses in gills of juvenile golden grey mullet (Liza aurata). Environmental Pollution 159, 2921-2928. 
Nelson, J.A., Claireaux, G., 2005. Sprint Swimming Performance of Juvenile European Sea Bass. Transactions of the American Fisheries Society 134, 1274-1284. doi:10.1577/T04-087.1

Nilsson, G.E., Östlund-Nilsson, S., 2008. Does size matter for hypoxia tolerance in fish? Biological Reviews 83, 173-189.

Nordvik, A.B., 1995. The technology windows-of-opportunity for marine oil spill response as related to oil weathering and operations. Spill Science \& Technology Bulletin 2, 17-46.

Oliveira, M., Gravato, C., Guilhermino, L., 2012. Acute toxic effects of pyrene on Pomatoschistus microps (Teleostei, Gobiidae): Mortality, biomarkers and swimming performance. Ecological Indicators 19, 206-214.

Pörtner, H.O., Knust, R., 2007. Climate change affects marine fishes through the oxygen limitation of thermal tolerance. science 315, 95-97.

Ramachandran, S.D., Hodson, P.V., Khan, C.W., Lee, K., 2004. Oil dispersant increases PAH uptake by fish exposed to crude oil. Ecotoxicology and Environmental Safety 59, 300-308. doi:10.1016/j.ecoenv.2003.08.018

Rosen, R., 1969. Hierarchical organization in automata theoretic models of the central nervous system, in: Information Processing in the Nervous System. Springer, pp. 21-35.

Sammarco, P.W., Kolian, S.R., Warby, R.A.F., Bouldin, J.L., Subra, W.A., Porter, S.A., 2013. Distribution and concentrations of petroleum hydrocarbons associated with the BP/Deepwater Horizon Oil Spill, Gulf of Mexico. Marine Pollution Bulletin 73, 129-143. doi:10.1016/j.marpolbul.2013.05.029

Schulte, P.M., 2015. The effects of temperature on aerobic metabolism: towards a mechanistic understanding of the responses of ectotherms to a changing environment. Journal of Experimental Biology 218, 1856-1866. doi:10.1242/jeb.118851

Short, J.W., Heintz, R.A., 1997. Identification of Exxon Valdez oil in sediments and tissues from Prince William Sound and the Northwestern Gulf of Alaska based on a PAH weathering model. Environmental science \& technology 31, 2375-2384.

Shoubridge, E.A., Hochachka, P.W., 1980. Ethanol: novel end product of vertebrate anaerobic metabolism. Science 209, 308-309. doi:10.1126/science.7384807

Simonato, J.D., Guedes, C.L., Martinez, C.B., 2008. Biochemical, physiological, and histological changes in the neotropical fish Prochilodus lineatus exposed to diesel oil. Ecotoxicology and Environmental Safety 69, 112-120.

Small, C., Nicholls, R.J., 2003. A global analysis of human settlement in coastal zones. Journal of Coastal Research 584-599.

Solomon, K.R., Brock, T.C.M., de Zwart, D., Dyer, S.D., Posthuma, L., Richards, S.M., Sanderson, H., Sibley, P.K., van den Brink, P.J., 2008. Extrapolation practice for ecotoxicological effect characterization of chemicals, SETAC Publications. CRC Press, Boca Raton.

Spooner, M., 1970. Oil spill in Tarut Bay, Saudi Arabia. Marine Pollution Bulletin 1, 166-167.

Stephen, C., 2014. Toward a modernized definition of wildlife health. J. Wildl. Dis. 50, 427-430. doi:10.7589/2013-11-305

Thomas, R.E., Rice, S.D., 1987. Effect of water-soluble fraction of cook inlet crude oil on swimming performance and plasma cortisol in juvenile coho salmon (Oncorhynchus kisutch). Comparative Biochemistry and Physiology Part C: Comparative Pharmacology 87, 177-180. doi:10.1016/0742-8413(87)90200-3

Thorarensen, H., Gallaugher, P., Farrell, A.P., 1996. Cardiac output in swimming rainbow trout, Oncorhynchus mykiss, acclimated to seawater. Physiological zoology 139-153.

Tierney, K.B., Farrell, A.P., 2004. The relationships between fish health, metabolic rate, swimming performance and recovery in return-run sockeye salmon, Oncorhynchus nerka (Walbaum). Journal of Fish Diseases 27, 663-671. doi:10.1111/j.1365-2761.2004.00590.x 
Varanasi, U., 1989. Metabolism of Polycyclic Aromatic Hydrocarbons in the Aquatic Environment. CRC Press.

\section{Figures legends}

Fig. 1: Study timeline.

Fig. 2: Water total petroleum concentration (mg/L) measured throughout the $48 \mathrm{~h}$ exposure period in tanks from the control (CONT; white bar), dispersant (DISP; white hatched bar), oil (OIL; grey bar) and chemically dispersed oil (OIL + DISP; grey hatched bar) treatments. $N=9$ (3 samples $\times 3$ replicate tanks). The error bars indicate the calculated SEM.

Fig. 3: Sum of the concentration (ng/g dry weight) in $21 \mathrm{PAH}$ measured two $(\mathrm{d}+2)$ and 31 days post-exposure $(d+31)$ in fish white muscle from the control (CONT; white bar), dispersant (DISP; white hatched bar), oil (OIL; grey bar) and chemically dispersed oil (OIL+DISP; grey hatched bar) treatments. $N=9$ (3 samples $\times 3$ replicate tanks). The error bars indicate the calculated SEM.

Fig. 4: Three months (1) and 11 months (2) repeatability of time to loss of equilibrium of control fish at hypoxia $(A)$; temperature challenge tests $(B)$ and time to reach exhaustion at swimming challenge test $(C)$. Performance repeatability of fish from the four treatments is summarized in D. Blank cells: significant correlation $(p<0.05)$, light grey cells: marginally significant correlation ( $p<0.07$ ); grey cells: no significant correlation. rs corresponds to the Spearman's rank correlation coefficient. 
Fig. 5: Fish count throughout the challenge test set \#2 (A: Hypoxia challenge test, $p=$ 0.01 ; B: Temperature challenge test, $p=0.03$; : Swimming challenge test $p=0.51$ ). Solid thick line: CONT; solid thin line: DISP; dashed line: OIL; pointed dashed line: OIL + DISP. Insets: barplots correspond to the median time to loss equilibrium (TLOE) or to reach exhaustion (TE). Error bars indicate the 95\% confidence interval calculated with the Kaplan-Meier survival analysis and * indicate statistical difference.

Fig. 6: Water condition in the earthen ponds. Measurements were made weekly in the 7 ponds $(\bigcirc$ : pond \#1, $\Delta$ : pond \#2, $\diamond$ : pond \#3, $\nabla$ : pond \#4, $\mathbf{a}:$ pond \#5, , pond \#6, $\mathbf{\Delta}$ : pond \#7).

Fig. 7: Daily relative growth rate measured for the 3 different periods according to A) the different ponds, B) the exposure condition. Black bars correspond to the MayJune period, grey bars to the July-August period and white bars to the SeptemberOctober period.

Fig. 8: Comparison of fish performances at challenge tests of fish that survived (white bars) or died (black bars) during each period in the ponds. The number of fish present in each group is indicated above the bars. The error bars indicate the calculated SEM and ${ }^{*}$ indicates statistically significant difference $(p<0.05)$. 
Fig. 1

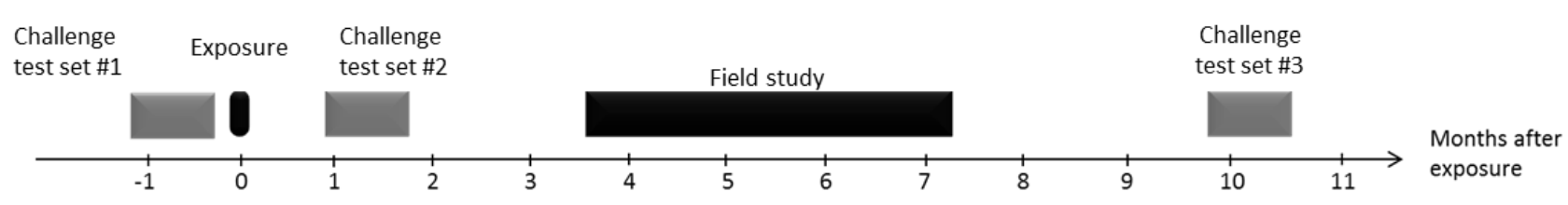


Fig. 2

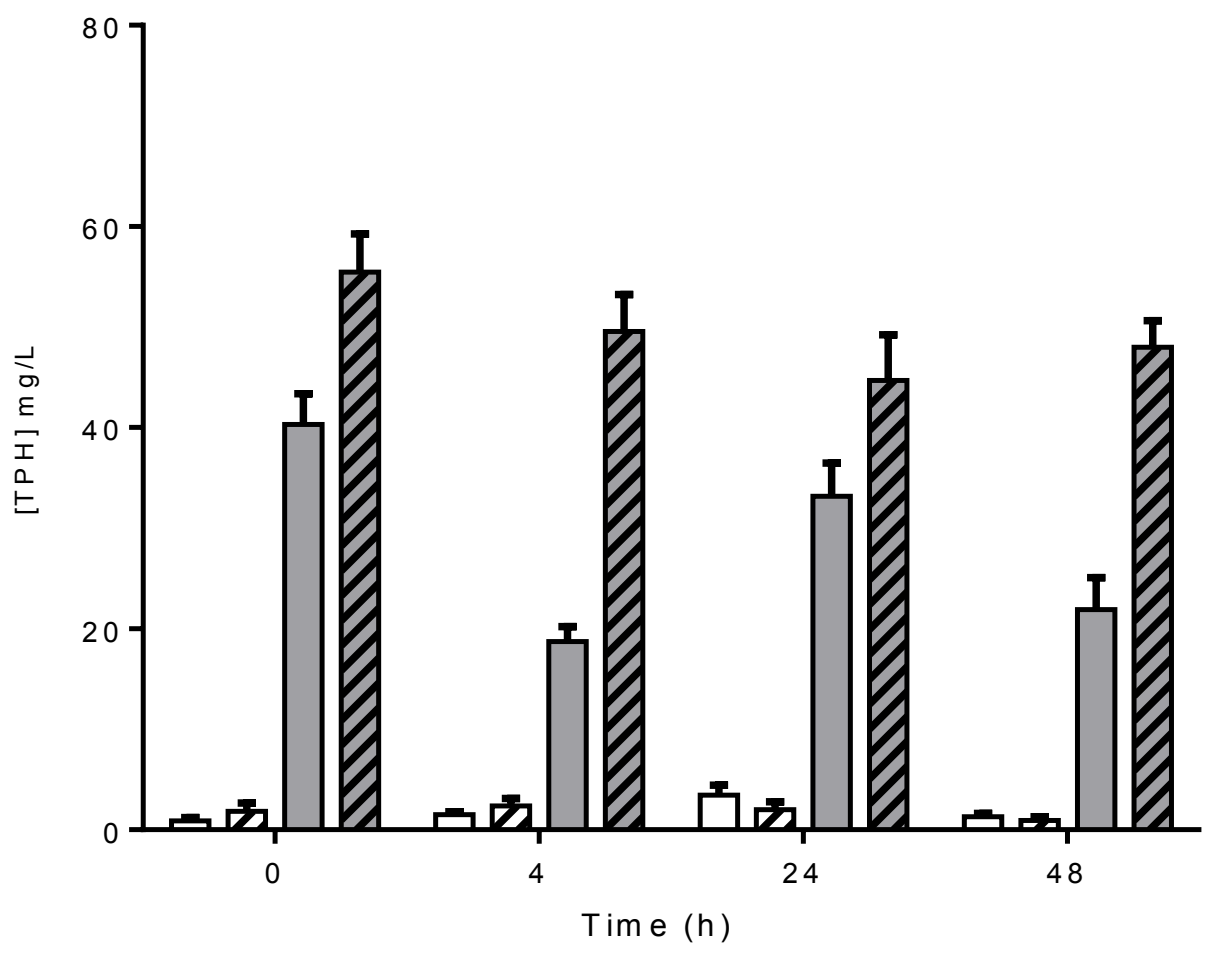

36 
Fig. 3

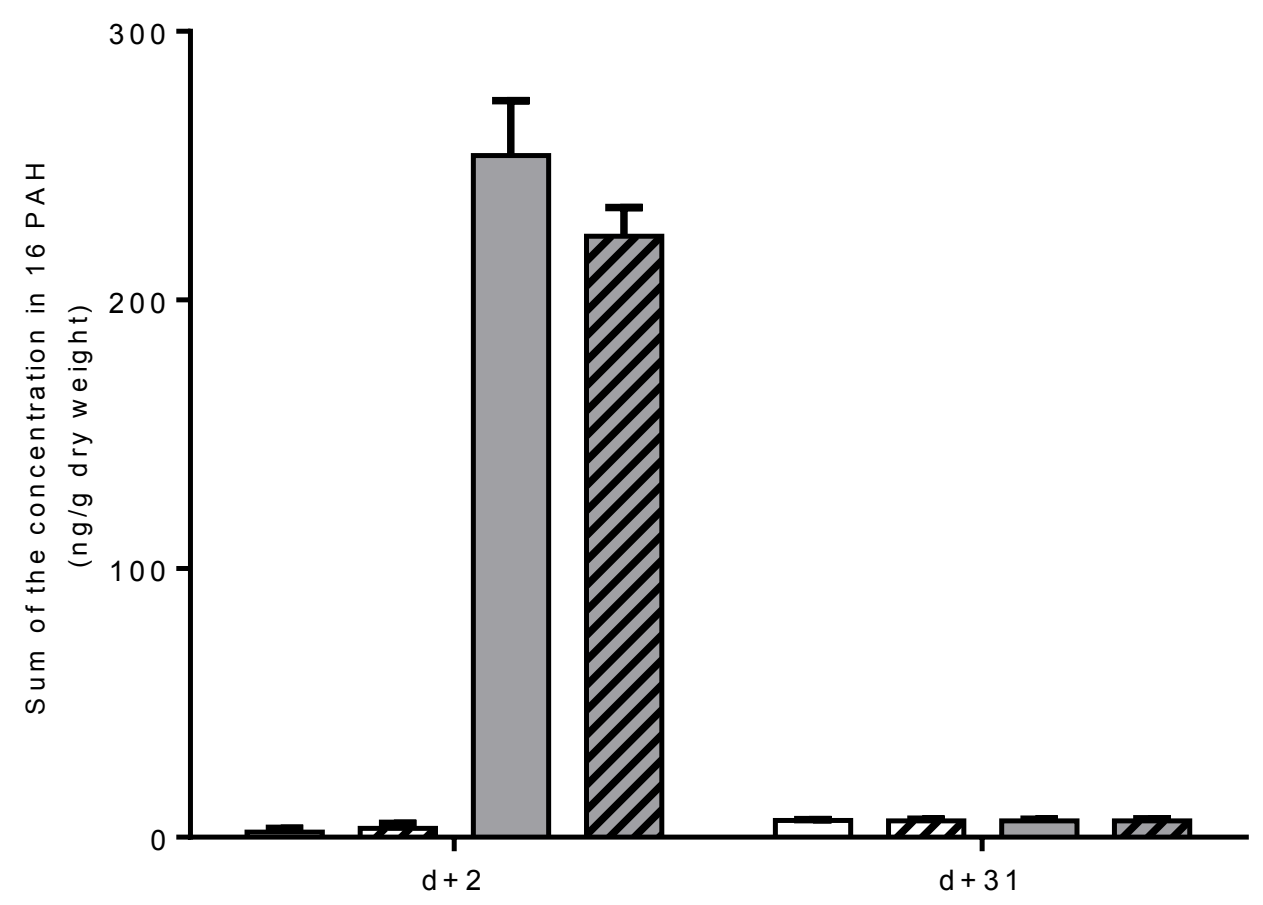


Fig. 4
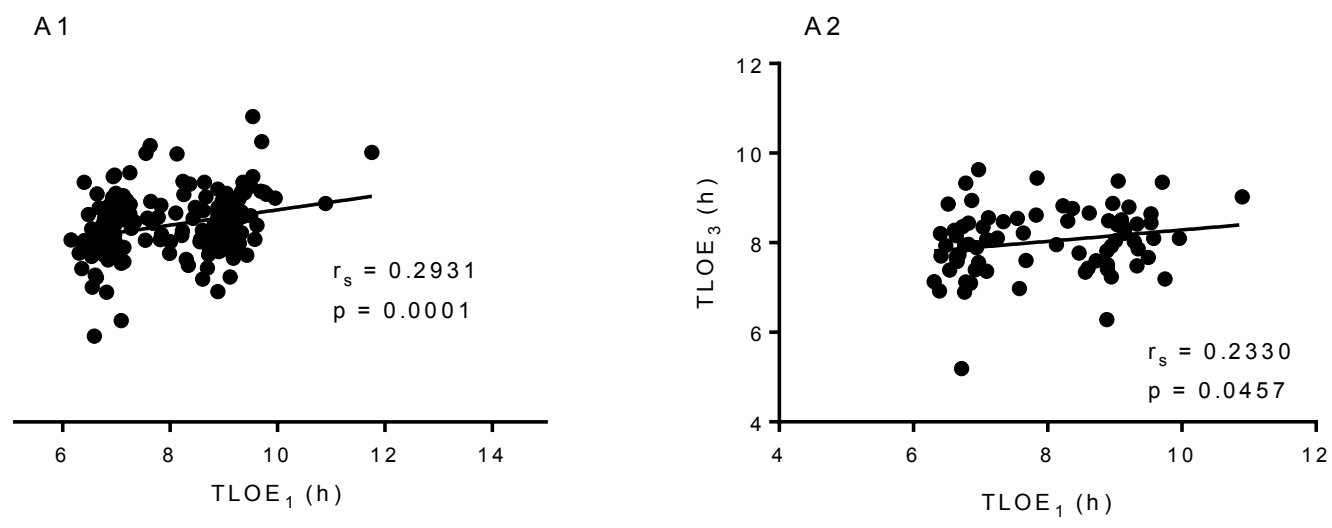

B 1
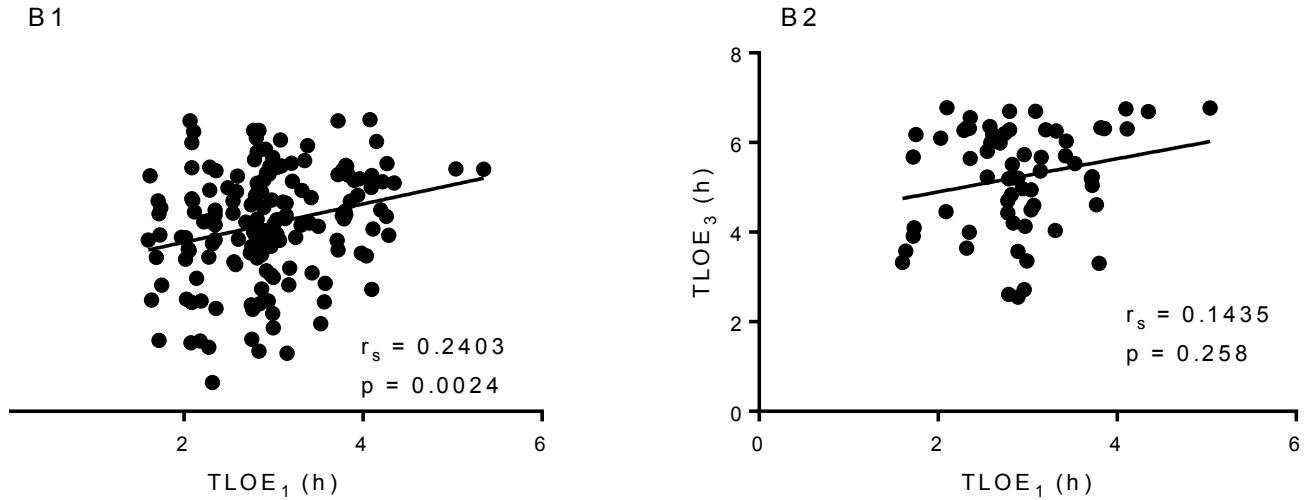

C 1 
D

\begin{tabular}{|c|c|cc|cc|cc|cc|}
\hline \multirow{2}{*}{ Challenge test } & \multirow{2}{*}{ Set } & \multicolumn{2}{|c|}{ CONT } & \multicolumn{2}{c|}{ DISP } & \multicolumn{2}{c|}{ OIL } & \multicolumn{2}{c|}{ OIL+DISP } \\
& & $r_{s}$ & $p$ value & $r_{s}$ & $p$ value & $r_{s}$ & $p$ value & $r_{s}$ & $p$ value \\
\hline \multirow{2}{*}{ Hypoxia } & 1 vs 2 & 0.2931 & 0.0001 & 0.1437 & 0.0615 & 0.2412 & 0.0016 & 0.2224 & 0.0035 \\
& 1 vs 3 & 0.233 & 0.0457 & -0.102 & 0.3226 & 0.2332 & 0.0307 & 0.1234 & 0.2464 \\
\hline \multirow{2}{*}{ Temperature } & 1 vs 2 & 0.2403 & 0.0024 & 0.2425 & 0.0019 & 0.2306 & 0.0034 & 0.1446 & 0.0681 \\
& 1 vs 3 & 0.1435 & 0.258 & 0.06377 & 0.5436 & -0.1387 & 0.2054 & -0.04411 & 0.6904 \\
\hline \multirow{2}{*}{ Swimming } & 1 vs 2 & 0.3652 & $<0.0001$ & 0.3524 & $<0.0001$ & 0.3217 & $<0.0001$ & 0.3146 & $<0.0001$ \\
& 1 vs 3 & 0.2897 & 0.0392 & 0.3021 & 0.0116 & 0.2613 & 0.0386 & 0.008588 & 0.9459 \\
\hline
\end{tabular}


Fig. 5

A

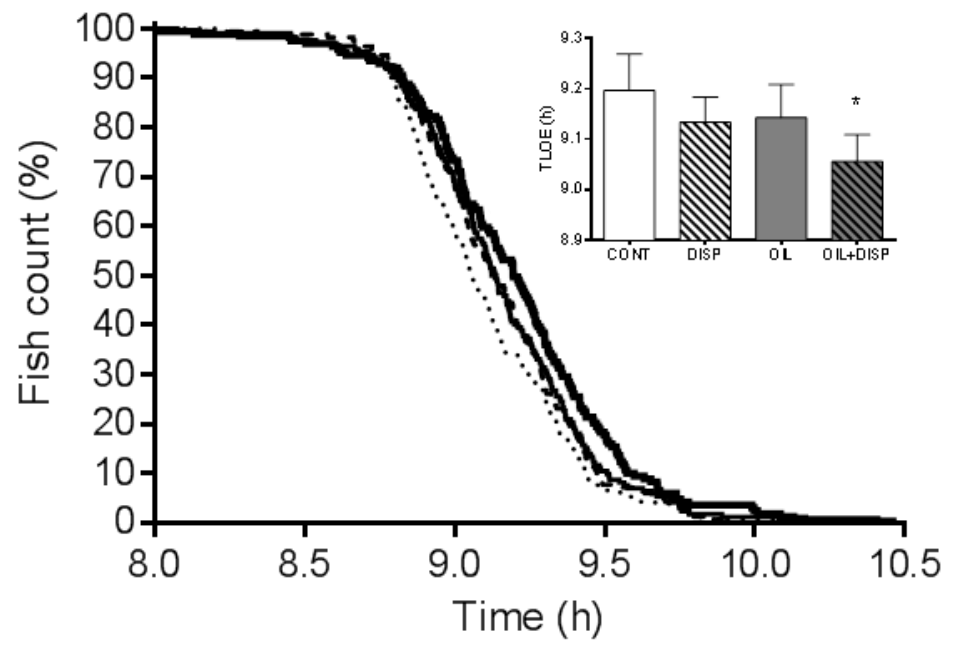

B

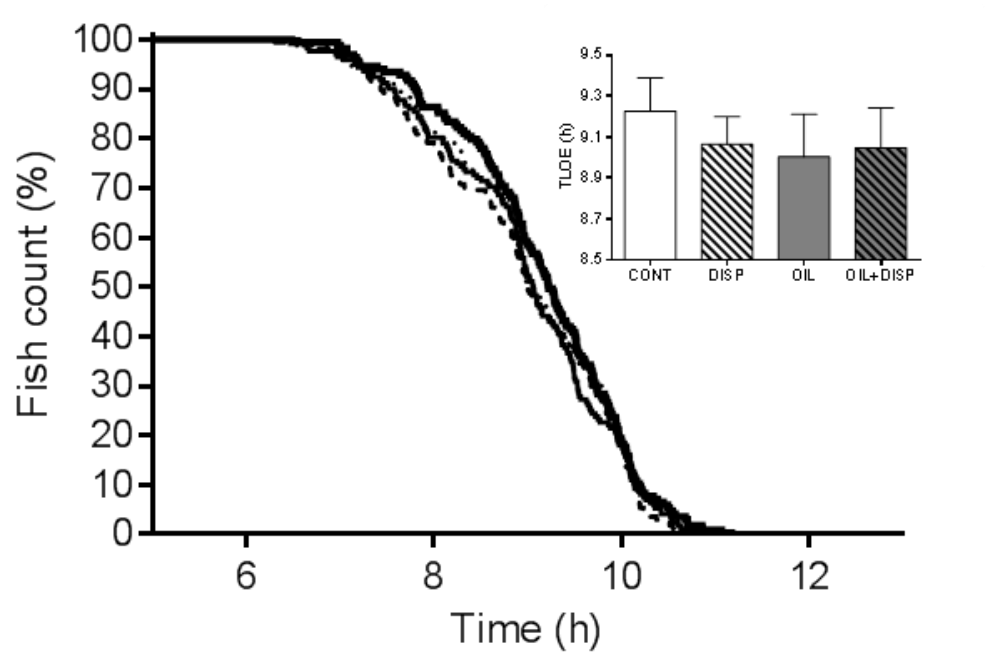


C

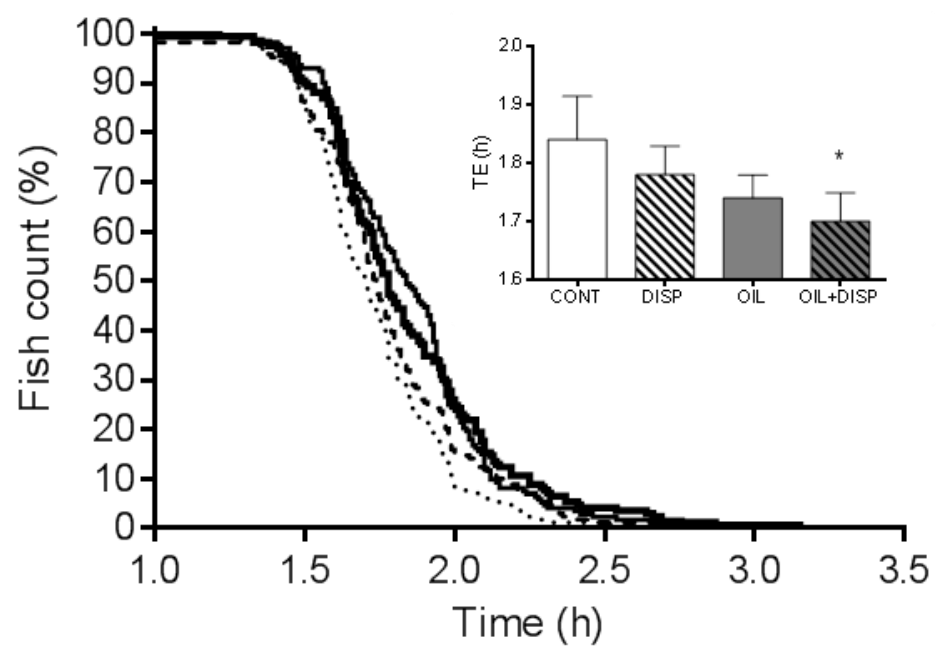


Fig. 6
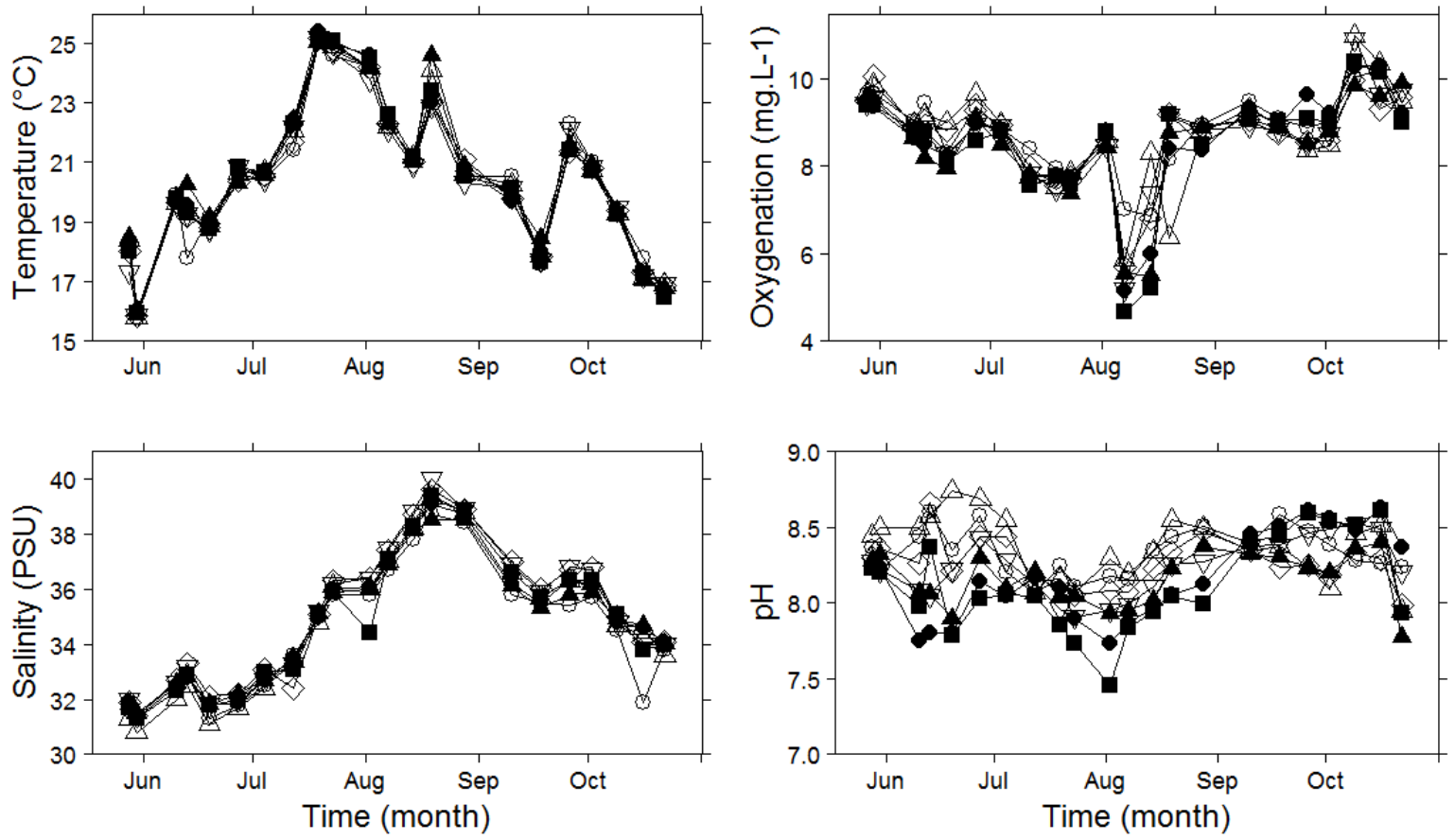
Fig. 7

A

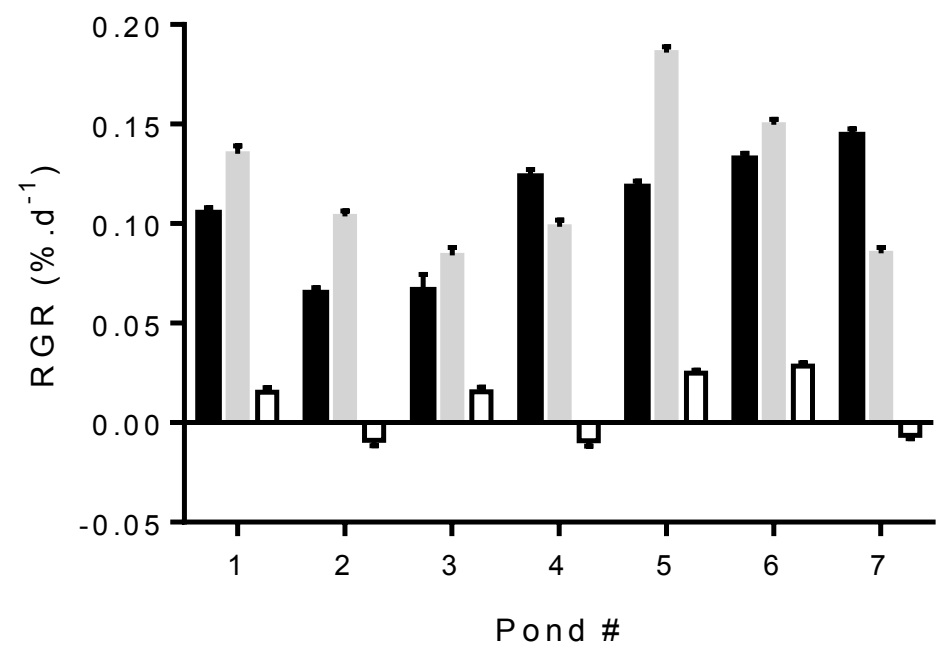

B

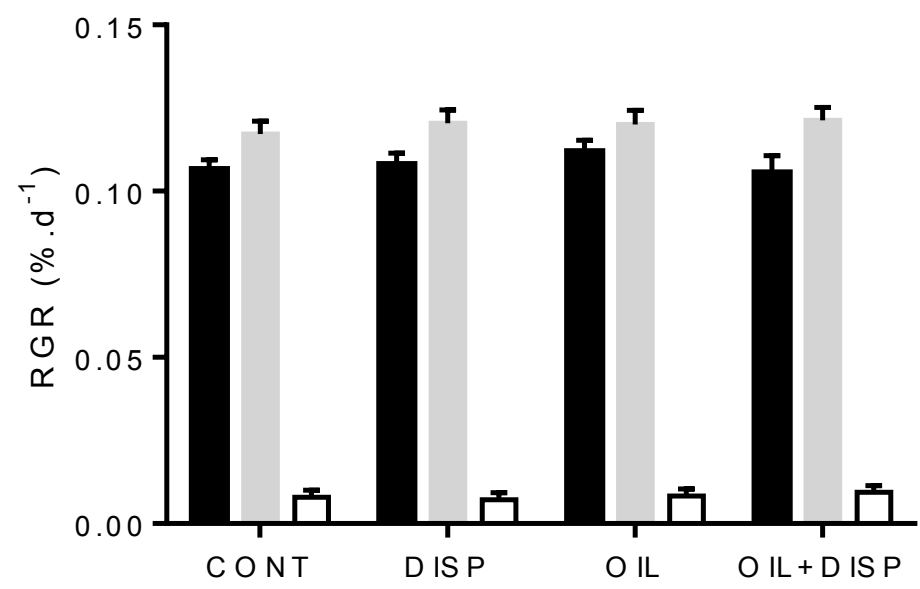


Fig. 8

A

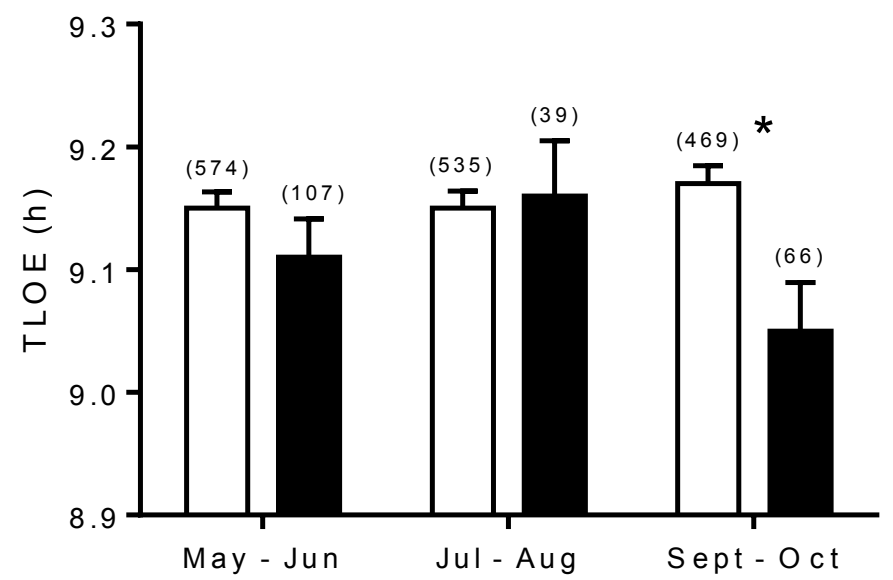

B

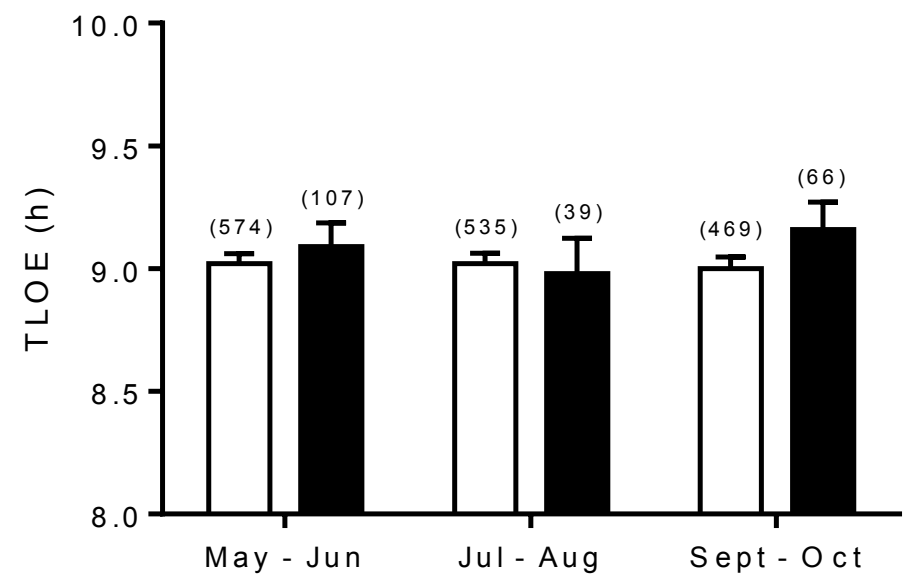


C

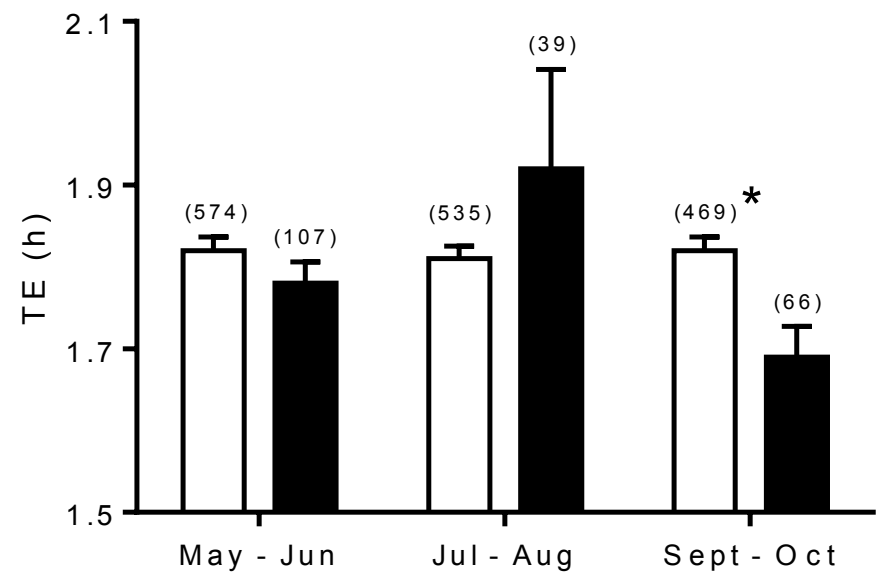




\section{Appendix}

Appendix 1: Concentration of $21 \mathrm{PAHs}$ (alkylated and parents) in fish white muscle from the four treatments measured 2 and 31 days post-exposure. The 21 PAHs represent the 16 US-EPA PAHs and five supplementary PAHs (benzo[b]thiophene, biphenyl, dibenzothiophene, benzo[e]pyrene, perylene). LOQ: Limit Of Quantification.

\begin{tabular}{|c|c|c|c|c|c|c|c|c|}
\hline \multirow[t]{3}{*}{$\mathrm{PAH}$} & \multicolumn{8}{|c|}{ Concentration $\pm \operatorname{sem}\left(\mathrm{ng}^{-1} \mathrm{~g}^{-1}\right)$ at 2 and 31 days post-exposure } \\
\hline & \multicolumn{4}{|c|}{$d+2$} & \multicolumn{4}{|c|}{$d+31$} \\
\hline & CONT & DISP & OIL & OIL+DISP & CONT & DISP & OIL & OIL+DISP \\
\hline Naphtalene & $<\mathrm{LOQ}$ & $<\mathrm{LOQ}$ & $6 \pm 1$ & $6 \pm 1$ & $<\mathrm{LOQ}$ & $<\mathrm{LOQ}$ & $<\mathrm{LOQ}$ & $<\mathrm{LOQ}$ \\
\hline Benzothiophene & $<\mathrm{LOQ}$ & $<\mathrm{LOQ}$ & $<\mathrm{LOQ}$ & $<\mathrm{LOQ}$ & $<\mathrm{LOQ}$ & $<\mathrm{LOQ}$ & $<\mathrm{LOQ}$ & $<\mathrm{LOQ}$ \\
\hline Biphenyl & $<\mathrm{LOQ}$ & $<\mathrm{LOQ}$ & $<\mathrm{LOQ}$ & $<\mathrm{LOQ}$ & $<\mathrm{LOQ}$ & $<\mathrm{LOQ}$ & $<\mathrm{LOQ}$ & $<\mathrm{LOQ}$ \\
\hline Acenaphtylene & $<\mathrm{LOQ}$ & $<\mathrm{LOQ}$ & $<\mathrm{LOQ}$ & $<\mathrm{LOQ}$ & $<\mathrm{LOQ}$ & $<\mathrm{LOQ}$ & $<\mathrm{LOQ}$ & $<\mathrm{LOQ}$ \\
\hline Acenaphtene & $<\mathrm{LOQ}$ & $<\mathrm{LOQ}$ & $<\mathrm{LOQ}$ & $<\mathrm{LOQ}$ & $<\mathrm{LOQ}$ & $<\mathrm{LOQ}$ & $<\mathrm{LOQ}$ & $<\mathrm{LOQ}$ \\
\hline Fluorene & $<\mathrm{LOQ}$ & $<\mathrm{LOQ}$ & $23 \pm 7$ & $8 \pm 3$ & $<\mathrm{LOQ}$ & $<\mathrm{LOQ}$ & $<\mathrm{LOQ}$ & $<\mathrm{LOQ}$ \\
\hline Dibenzothiophene & $<\mathrm{LOQ}$ & $<L O Q$ & $203 \pm 17$ & $185 \pm 11$ & $<\mathrm{LOQ}$ & $<\mathrm{LOQ}$ & $<\mathrm{LOQ}$ & $<\mathrm{LOQ}$ \\
\hline Phenanthrene & $<\mathrm{LOQ}$ & $<\mathrm{LOQ}$ & $28 \pm 3$ & $25 \pm 2$ & $<\mathrm{LOQ}$ & $<\mathrm{LOQ}$ & $<\mathrm{LOQ}$ & $<\mathrm{LOQ}$ \\
\hline Anthracene & $<\mathrm{LOQ}$ & $<\mathrm{LOQ}$ & $<\mathrm{LOQ}$ & $<\mathrm{LOQ}$ & $<\mathrm{LOQ}$ & $<L O Q$ & $<\mathrm{LOQ}$ & $<\mathrm{LOQ}$ \\
\hline Fluoranthene & $<\mathrm{LOQ}$ & $<\mathrm{LOQ}$ & $<\mathrm{LOQ}$ & $<\mathrm{LOQ}$ & $<\mathrm{LOQ}$ & $<\mathrm{LOQ}$ & $<\mathrm{LOQ}$ & $<\mathrm{LOQ}$ \\
\hline Pyrene & $<\mathrm{LOQ}$ & $<\mathrm{LOQ}$ & $<\mathrm{LOQ}$ & $<\mathrm{LOQ}$ & $<\mathrm{LOQ}$ & $<L O Q$ & $<\mathrm{LOQ}$ & $<\mathrm{LOQ}$ \\
\hline Benzoaanthracene & $<\mathrm{LOQ}$ & $<\mathrm{LOQ}$ & $<\mathrm{LOQ}$ & $<\mathrm{LOQ}$ & $<\mathrm{LOQ}$ & $<L O Q$ & $<\mathrm{LOQ}$ & $<\mathrm{LOQ}$ \\
\hline Chrysene & $<\mathrm{LOQ}$ & $<\mathrm{LOQ}$ & $<\mathrm{LOQ}$ & $<\mathrm{LOQ}$ & $<\mathrm{LOQ}$ & $<\mathrm{LOQ}$ & $<\mathrm{LOQ}$ & $<\mathrm{LOQ}$ \\
\hline Benzo[b]fluoranthene & $<\mathrm{LOQ}$ & $<\mathrm{LOQ}$ & $<\mathrm{LOQ}$ & $<\mathrm{LOQ}$ & $<\mathrm{LOQ}$ & $<L O Q$ & $<\mathrm{LOQ}$ & $<\mathrm{LOQ}$ \\
\hline Benzo[k]fluoranthene & $<\mathrm{LOQ}$ & $<\mathrm{LOQ}$ & $<\mathrm{LOQ}$ & $<\mathrm{LOQ}$ & $<\mathrm{LOQ}$ & $<\mathrm{LOQ}$ & $<\mathrm{LOQ}$ & $<\mathrm{LOQ}$ \\
\hline Benzo[e]pyrene & $<\mathrm{LOQ}$ & $<\mathrm{LOQ}$ & $<\mathrm{LOQ}$ & $<\mathrm{LOQ}$ & $<\mathrm{LOQ}$ & $<\mathrm{LOQ}$ & $<\mathrm{LOQ}$ & $<\mathrm{LOQ}$ \\
\hline Benzo[a]pyrene & $<\mathrm{LOQ}$ & $<\mathrm{LOQ}$ & $<\mathrm{LOQ}$ & $<\mathrm{LOQ}$ & $<\mathrm{LOQ}$ & $<\mathrm{LOQ}$ & $<\mathrm{LOQ}$ & $<\mathrm{LOQ}$ \\
\hline Perylene & $<\mathrm{LOQ}$ & $<\mathrm{LOQ}$ & $<\mathrm{LOQ}$ & $<\mathrm{LOQ}$ & $<\mathrm{LOQ}$ & $<\mathrm{LOQ}$ & $<\mathrm{LOQ}$ & $<\mathrm{LOQ}$ \\
\hline Indeno[1,2,3-cd]pyrene & $<\mathrm{LOQ}$ & $<\mathrm{LOQ}$ & $<\mathrm{LOQ}$ & $<\mathrm{LOQ}$ & $<\mathrm{LOQ}$ & $<\mathrm{LOQ}$ & $<\mathrm{LOQ}$ & $<\mathrm{LOQ}$ \\
\hline Dibenzo[a, h]anthracene & $<\mathrm{LOQ}$ & $<\mathrm{LOQ}$ & $<\mathrm{LOQ}$ & $<\mathrm{LOQ}$ & $<\mathrm{LOQ}$ & $<\mathrm{LOQ}$ & $<\mathrm{LOQ}$ & $<\mathrm{LOQ}$ \\
\hline Benzoperylene & $<\mathrm{LOQ}$ & $<\mathrm{LOQ}$ & $<\mathrm{LOQ}$ & $<\mathrm{LOQ}$ & $<\mathrm{LOQ}$ & $<\mathrm{LOQ}$ & $<\mathrm{LOQ}$ & $<\mathrm{LOQ}$ \\
\hline Mean of individual's [21 PAH] & 1 & 1 & $259 \pm 24$ & $224 \pm 33$ & 1 & 1 & I & 1 \\
\hline
\end{tabular}

